\title{
Management of bleeding following major trauma: an updated European guideline
}

\author{
Rolf Rossaint ${ }^{1}$, Bertil Bouillon², Vladimir Cerny ${ }^{3}$, Timothy J Coats ${ }^{4}$, Jacques Duranteau ${ }^{5}$, \\ Enrique Fernández-Mondéjar ${ }^{6}$, Beverley J Hunt ${ }^{7}$, Radko Komadina ${ }^{8}$, Giuseppe Nardii, Edmund Neugebauer ${ }^{10}$, \\ Yves Ozier ${ }^{11}$, Louis Riddez ${ }^{12}$, Arthur Schultz ${ }^{13}$, Philip F Stahel ${ }^{14}$, Jean-Louis Vincent ${ }^{15}$, Donat R Spahn ${ }^{16^{*}}$
}

\begin{abstract}
Introduction: Evidence-based recommendations are needed to guide the acute management of the bleeding trauma patient, which when implemented may improve patient outcomes.

Methods: The multidisciplinary Task Force for Advanced Bleeding Care in Trauma was formed in 2005 with the aim of developing a guideline for the management of bleeding following severe injury. This document presents an updated version of the guideline published by the group in 2007. Recommendations were formulated using a nominal group process, the Grading of Recommendations Assessment, Development and Evaluation (GRADE) hierarchy of evidence and based on a systematic review of published literature.

Results: Key changes encompassed in this version of the guideline include new recommendations on coagulation support and monitoring and the appropriate use of local haemostatic measures, tourniquets, calcium and desmopressin in the bleeding trauma patient. The remaining recommendations have been reevaluated and graded based on literature published since the last edition of the guideline. Consideration was also given to changes in clinical practice that have taken place during this time period as a result of both new evidence and changes in the general availability of relevant agents and technologies.
\end{abstract}

Conclusions: This guideline provides an evidence-based multidisciplinary approach to the management of critically injured bleeding trauma patients.

\section{Introduction}

Uncontrolled post-traumatic bleeding is the leading cause of potentially preventable death among trauma patients [1,2]. About one-third of all trauma patients with bleeding present with a coagulopathy on hospital admission [3-5]. This subset of patients has a significantly increased incidence of multiple organ failure and death compared to patients with similar injury patterns in the absence of a coagulopathy $[3,5,6]$. Appropriate management of the trauma patient with massive bleeding, defined here as the loss of one blood volume within 24 hours or the loss of 0.5 blood volumes within 3 hours, includes the early identification of potential bleeding sources followed by prompt measures to minimise blood loss, restore tissue perfusion and achieve

\footnotetext{
* Correspondence: donat.spahn@usz.ch

${ }^{16}$ Institute of Anesthesiology, University Hospital Zurich, 8091 Zurich,
} Switzerland haemodynamic stability. Confounding factors include co-morbidities, pre-medication and physical parameters that contribute to a coagulopathic state $[7,8]$.

The early acute coagulopathy associated with traumatic injury has recently been recognised as a multifactorial primary condition that results from a combination of shock, tissue injury-related thrombin generation and the activation of anticoagulant and fibrinolytic pathways. The condition is influenced by environmental and therapeutic factors that contribute to acidaemia, hypothermia, dilution, hypoperfusion and haemostasis factor consumption [3,4,8-11]. A number of terms have been proposed to describe the condition, which is distinct from disseminated intravascular coagulation, including acute traumatic coagulopathy [4], early coagulopathy of trauma [5], acute coagulopathy of trauma-shock [8] and trauma-induced coagulopathy [12]. With the evolution of the concept of an early post-traumatic coagulopathic 
state, it may be appropriate to reassess some data from the past, and with time new research will doubtless lead to a better understanding of the risks and benefits of different therapeutic approaches applied to this group of patients.

In 2007, we published a European guideline for the management of bleeding following major trauma that included recommendations for specific interventions to identify and control bleeding sources using surgical, physiological and pharmacological strategies [13]. The guideline was developed by a multidisciplinary group of European experts, including designated representatives from relevant professional societies, to guide the clinician in the early phases of treatment. Here we present an updated version of the guideline that incorporates a renewed critical survey of the evidence published during the intervening three years and a consideration of changes in clinical practice that have taken place based on technologies that have become more widely available and pharmacological agents that have entered or left the market. Although the level of scientific evidence has improved in some areas, other areas remain devoid of high-level evidence, which may never exist for practical or ethical reasons. The formulation and grading of the recommendations presented here are therefore weighted to reflect both this reality and the current state-ofthe-art.

\section{Materials and methods}

These recommendations were formulated and graded according the Grading of Recommendations Assessment, Development and Evaluation (GRADE) hierarchy of evidence [14-16] summarised in Table 1. Comprehensive computer database literature searches were performed using the indexed online databases MEDLINE/ PubMed and the Cochrane Library. Lists of cited literature within relevant articles were also screened. The primary intention of the review was to identify prospective randomised controlled trials (RCTs) and non-RCTs, existing systematic reviews and guidelines. In the absence of such evidence, case-control studies, observational studies and case reports were considered.

Boolean operators and Medical Subject Heading $(\mathrm{MeSH})$ thesaurus keywords were applied as a standardised use of language to unify differences in terminology into single concepts. Appropriate $\mathrm{MeSH}$ headings and

Table 1 Grading of recommendations from Guyatt and colleagues [14]

\begin{tabular}{|c|c|c|c|}
\hline $\begin{array}{l}\text { Grade of } \\
\text { recommendation }\end{array}$ & Clarity of risk/benefit & Quality of supporting evidence & Implications \\
\hline \multicolumn{4}{|l|}{$\overline{1 A}$} \\
\hline $\begin{array}{l}\text { Strong } \\
\text { recommendation, } \\
\text { high-quality evidence }\end{array}$ & $\begin{array}{l}\text { Benefits clearly outweigh risk and } \\
\text { burdens, or vice versa }\end{array}$ & $\begin{array}{l}\text { RCTs without important limitations or } \\
\text { overwhelming evidence from observational } \\
\text { studies }\end{array}$ & $\begin{array}{l}\text { Strong recommendation, can } \\
\text { apply to most patients in most } \\
\text { circumstances without reservation }\end{array}$ \\
\hline \multicolumn{4}{|l|}{ 1B } \\
\hline $\begin{array}{l}\text { Strong } \\
\text { recommendation, } \\
\text { moderate-quality } \\
\text { evidence }\end{array}$ & $\begin{array}{l}\text { Benefits clearly outweigh risk and } \\
\text { burdens, or vice versa }\end{array}$ & $\begin{array}{l}\text { RCTs with important limitations (inconsistent } \\
\text { results, methodological flaws, indirect or } \\
\text { imprecise) or exceptionally strong evidence from } \\
\text { observational studies }\end{array}$ & $\begin{array}{l}\text { Strong recommendation, can } \\
\text { apply to most patients in most } \\
\text { circumstances without reservation }\end{array}$ \\
\hline \multicolumn{4}{|l|}{$1 C$} \\
\hline $\begin{array}{l}\text { Strong } \\
\text { recommendation, } \\
\text { low-quality or very } \\
\text { low-quality evidence }\end{array}$ & $\begin{array}{l}\text { Benefits clearly outweigh risk and } \\
\text { burdens, or vice versa }\end{array}$ & Observational studies or case series & $\begin{array}{l}\text { Strong recommendation but may } \\
\text { change when higher quality } \\
\text { evidence becomes available }\end{array}$ \\
\hline \multicolumn{4}{|l|}{$2 A$} \\
\hline $\begin{array}{l}\text { Weak } \\
\text { recommendation, } \\
\text { high-quality evidence }\end{array}$ & $\begin{array}{l}\text { Benefits closely balanced with risks } \\
\text { and burden }\end{array}$ & $\begin{array}{l}\text { RCTs without important limitations or } \\
\text { overwhelming evidence from observational } \\
\text { studies }\end{array}$ & $\begin{array}{l}\text { Weak recommendation, best } \\
\text { action may differ depending on } \\
\text { circumstances or patient or } \\
\text { societal values }\end{array}$ \\
\hline \multicolumn{4}{|l|}{ 2B } \\
\hline $\begin{array}{l}\text { Weak } \\
\text { recommendation, } \\
\text { moderate-quality } \\
\text { evidence }\end{array}$ & $\begin{array}{l}\text { Benefits closely balanced with risks } \\
\text { and burden }\end{array}$ & $\begin{array}{l}\text { RCTs with important limitations (inconsistent } \\
\text { results, methodological flaws, indirect or } \\
\text { imprecise) or exceptionally strong evidence from } \\
\text { observational studies }\end{array}$ & $\begin{array}{l}\text { Weak recommendation, best } \\
\text { action may differ depending on } \\
\text { circumstances or patient or } \\
\text { societal values }\end{array}$ \\
\hline \multicolumn{4}{|l|}{$2 C$} \\
\hline $\begin{array}{l}\text { Weak } \\
\text { recommendation, } \\
\text { Low-quality or very } \\
\text { low-quality evidence }\end{array}$ & $\begin{array}{l}\text { Uncertainty in the estimates of } \\
\text { benefits, risks, and burden; benefits, } \\
\text { risk and burden may be closely } \\
\text { balanced }\end{array}$ & Observational studies or case series & $\begin{array}{l}\text { Very weak recommendation; other } \\
\text { alternatives may be equally } \\
\text { reasonable }\end{array}$ \\
\hline
\end{tabular}


subheadings for each question were selected and modified based on search results. The scientific questions posed that led to each recommendation and the $\mathrm{MeSH}$ headings applied to each search are listed in Additional file 1. Searches were limited to English language abstracts and human studies, and gender and age were not limited. The time period was limited to the past three years for questions addressed in the 2007 version of the guideline, but no time-period limits were imposed on new searches. Original publications were evaluated for abstracts that were deemed relevant. Original publications were graded according to the levels of evidence developed by the Oxford Centre for Evidence-Based Medicine (Oxford, Oxfordshire, UK) [17].

The selection of the scientific enquiries to be addressed in the guideline, screening and grading of the literature to be included and formulation of specific recommendations were performed by members of the Task Force for Advanced Bleeding Care in Trauma, a multidisciplinary, pan-European group of experts with specialties in surgery, anaesthesia, emergency medicine, intensive care medicine and haematology. The core group was formed in 2004 to produce educational material on the care of the bleeding trauma patient [18], on which an update (in 2006) and subsequent review article were based [19]. The task force consisted of the core group, additional experts in haematology and guideline development, and representatives of relevant European professional societies, including the European Society of Anaesthesiology, the European Society of Intensive Care Medicine, the European Shock Society, the European Society of Trauma and Emergency Surgery and the European Society for Emergency Medicine. The European Hematology Association declined the invitation to designate a representative to join the task force.

As part of the guideline development process that led to the 2007 guideline, task force members participated in a workshop on the critical appraisal of medical literature. The nominal group process for the updated guideline included several remote (telephone and web-based) meetings and one face-to-face meeting supplemented by several Delphi rounds [20]. The guideline development group participated in a web conference in March 2009 to define the scientific questions to be addressed in the guideline. Selection, screening and grading of the literature and formulation of recommendations were accomplished in subcommittee groups consisting of at least three members via electronic or telephone communication. After distribution of the recommendations to the entire group, a face-to-face meeting of the task force was held in June 2009 with the aim of reaching a consensus on the draft recommendations from each subcommittee. After final refinement of the rationale for each recommendation and the complete manuscript, the updated document was approved by the endorsing organisations between October 2009 and January 2010. An updated version of the guideline is anticipated in due time.

In the GRADE system for assessing each recommendation, the letter attached to the grade of recommendation reflects the degree of literature support for the recommendation, whereas the number indicates the level of support for the recommendation assigned by the committee of experts. Recommendations are grouped by category and somewhat chronologically in the treatment decision-making process, but not by priority or hierarchy.

\section{Results}

I. Initial resuscitation and prevention of further bleeding Minimal elapsed time

Recommendation 1 We recommend that the time elapsed between injury and operation be minimised for patients in need of urgent surgical bleeding control (Grade 1A).

Rationale Trauma patients in need of emergency surgery for ongoing haemorrhage have increased survival if the elapsed time between the traumatic injury and admission to the operating theatre is minimised. More than $50 \%$ of all trauma patients with a fatal outcome die within 24 hours of injury [2]. Despite a lack of evidence from prospective RCTs, well-designed retrospective studies provide evidence for early surgical intervention in patients with traumatic haemorrhagic shock [21-23].

In addition, studies that analyse trauma systems indirectly emphasise the importance of minimising the time between admission and surgical bleeding control in patients with traumatic haemorrhagic shock [24,25]. At present, the evidence base for the impact of the implementation of the Advanced Trauma Life Support (ATLS) protocol on patient outcome is very poor, because the available literature focuses primarily on the effectiveness of ATLS as an educational tool [26]. Future studies are needed to define the impact of the ATLS program within trauma systems at the hospital and health system level in terms of controlled before-andafter implementation designed to assess post-injury mortality as the primary outcome parameter.

\section{Tourniquet use}

Recommendation 2 We recommend adjunct tourniquet use to stop life-threatening bleeding from open extremity injuries in the pre-surgical setting (Grade 1C).

Rationale Much discussion has been generated recently regarding the use of tourniquets for acute external haemorrhage control. Pressure bandages rather than tourniquets should be applied in the case of minor bleeding from open wounds in extremity injuries. When uncontrolled arterial bleeding occurs from mangled extremity injuries, including penetrating or blast injuries or 
traumatic amputations, a tourniquet represents a simple and efficient method to acutely control haemorrhage [27-31]. Several publications from military settings report the effectiveness of tourniquets in this specific setting [27-30]. A study of volunteers showed that any tourniquet device presently on the market works efficiently [31]. The study also showed that 'pressure point control' was ineffective because collateral circulation was observed within seconds. Tourniquet-induced pain was not an important consideration.

Tourniquets should be left in place until surgical control of bleeding is achieved [28,30]; however, this timespan should be kept as short as possible. Improper or prolonged placement of a tourniquet can lead to complications such as nerve paralysis and limb ischaemia [32]. Some publications suggest a maximum time of application of two hours [32]. Reports from military settings report cases in which tourniquets have remained in place for up to six hours with survival of the extremity [28].

\section{Diagnosis and monitoring of bleeding Initial assessment}

Recommendation 3 We recommend that the physician clinically assess the extent of traumatic haemorrhage using a combination of mechanism of injury, patient physiology, anatomical injury pattern and the patient's response to initial resuscitation (Grade $1 \mathrm{C}$ ).

Rationale The mechanism of injury represents an important screening tool to identify patients at risk for significant traumatic haemorrhage. For example, the American College of Surgeons defined a threshold of $6 \mathrm{~m}(20 \mathrm{ft})$ as a 'critical falling height' associated with major injuries [33]. Further critical mechanisms include blunt versus penetrating trauma, high-energy deceleration impact, low-velocity versus high-velocity gunshot injuries, etc. The mechanism of injury in conjunction with injury severity, as defined by trauma scoring systems, and the patient's physiological presentation and response to resuscitation should further guide the decision to initiate early surgical bleeding control as outlined in the ATLS protocol [34-37]. Table 2 summarises estimated blood loss based on intitial presentation. Table 3 characterises the three types of response to initial fluid resuscitation, whereby the transient responders and the non-responders are candidates for immediate surgical bleeding control.

\section{Ventilation}

Recommendation 4 We recommend initial normoventilation of trauma patients if there are no signs of imminent cerebral herniation (Grade $1 C$ ).

Rationale Ventilation can affect the outcome of severe trauma patients. There is a tendency for rescue personnel to hyperventilate patients during resuscitation $[38,39]$, and hyperventilated trauma patients appear to have increased mortality when compared with nonhyperventilated patients [39].

A high percentage of severely injured patients with ongoing bleeding have traumatic brain injury (TBI). Relevant experimental and clinical data have shown that routine hyperventilation is an important contributor to adverse outcomes in patients with head injuries; however, the effect of hyperventilation on outcome in patients with severe trauma but no TBI is still a matter of debate. A low partial pressure of arterial carbon dioxide on admission to the emergency room is associated with a worse outcome in trauma patients with TBI [40-43].

There are several potential mechanisms for the adverse effects of hyperventilation and hypocapnia, including increased vasoconstriction with decreased cerebral blood flow and impaired tissue perfusion. In the setting of absolute or relative hypovolaemia, an excessive ventilation rate of positive-pressure ventilation may further compromise venous return and produce hypotension and even cardiovascular collapse $[41,42]$. It has

Table 2 American College of Surgeons Advanced Trauma Life Support (ATLS) classification of blood loss based on initial patient presentation

\begin{tabular}{|c|c|c|c|c|}
\hline & Class I & Class II & Class III & Class IV \\
\hline Blood loss* $(\mathrm{ml})$ & Up to750 & $750-1500$ & $1500-2000$ & $>2000$ \\
\hline Blood loss ( $\%$ blood volume) & Up to $15 \%$ & $15 \%-30 \%$ & $30 \%-40 \%$ & $>40 \%$ \\
\hline Pulse rate & $<100$ & $100-120$ & $120-140$ & $>140$ \\
\hline Blood pressure & Normal & Normal & Decreased & Decreased \\
\hline Pulse pressure (mmHg) & Normal or increased & Decreased & Decreased & Decreased \\
\hline Respiratory rate & $14-20$ & $20-30$ & $30-40$ & $>35$ \\
\hline Urine output (ml/h) & $>30$ & $20-30$ & $5-15$ & Negligible \\
\hline Central nervous system/mental status & Slightly anxious & Mildly anxious & Anxious, confused & Confused, lethargic \\
\hline Fluid replacement & Crystalloid & Crystalloid & Crystalloid and blood & Crystalloid and blood \\
\hline
\end{tabular}

Table reprinted with permission from the American College of Surgeons [37].

*for a $70 \mathrm{~kg}$ male. 
Table 3 American College of Surgeons Advanced Trauma Life Support (ATLS) responses to initial fluid resuscitation*

\begin{tabular}{llll}
\hline & Rapid response & Transient response & Minimal or no response \\
\hline Vital signs & Return to normal & $\begin{array}{l}\text { Transient improvement, recurrence } \\
\text { of decreased blood pressure and } \\
\text { increased heart rate }\end{array}$ & Remain abnormal \\
Estimated blood loss & Minimal (10\%-20\%) & Moderate and ongoing (20\%-40\%) & Severe (>40\%) \\
Need for more crystalloid & Low & High & High \\
Need for blood & Low & Moderate to high & Immediate \\
Blood preparation & Type and crossmatch & Type-specific & Emergency blood release \\
Need for operative intervention & Possibly & Likely & Highly likely \\
Early presence of surgeon & Yes & Yes & Yes \\
\hline
\end{tabular}

* $2000 \mathrm{ml}$ of isotonic solution in adults; $20 \mathrm{ml} / \mathrm{kg}$ bolus of Ringer's lactate in children.

Table reprinted with permission from the American College of Surgeons [37].

also been shown that cerebral tissue lactic acidosis occurs almost immediately after induction of hypocapnia in children and adults with TBI and haemorrhagic shock [44]. In addition, even a modest level of hypocapnia $(<27 \mathrm{mmHg})$ may result in neuronal depolarisation with glutamate release and extension of the primary injury via apoptosis [45].

Ventilation with low tidal volume is recommended in patients with acute lung injury. In patients with normal lung function, the evidence is scarce, but some observational studies show that the use of a high tidal volume is an important risk factor for the development of lung injury $[46,47]$. The injurious effect of high tidal volume may be initiated very early. Randomised studies demonstrate that short-time ventilation $(<$ five hours) with high tidal volume $(12 \mathrm{ml} / \mathrm{kg})$ without positive end-expiratory pressure (PEEP) may promote pulmonary inflammation and alveolar coagulation in patients with normal lung function [48]. Although more studies are needed, the early use of protective ventilation with low tidal volume and moderate PEEP is recommended, particularly in bleeding trauma patients at risk of acute lung injury.

\section{Immediate intervention}

Recommendation 5 We recommend that patients presenting with haemorrhagic shock and an identified source of bleeding undergo an immediate bleeding control procedure unless initial resuscitation measures are successful (Grade 1B).

Rationale The source of bleeding may be immediately obvious, and penetrating injuries are more likely to require surgical bleeding control. In a retrospective study of 106 abdominal vascular injuries, all 41 patients arriving in shock following gunshot wounds were candidates for rapid transfer to the operating theatre for surgical bleeding control [49]. A similar observation in a study of 271 patients undergoing immediate laparotomy for gunshot wounds indicates that these wounds combined with signs of severe hypovolaemic shock specifically require early surgical bleeding control. This observation is also true but to a lesser extent for abdominal stab wounds [50]. Data on injuries caused by penetrating metal fragments from explosives or gunshot wounds in the Vietnam War confirm the need for early surgical control when patients present in shock [51]. In blunt trauma, the mechanism of injury can determine to a certain extent whether the patient in haemorrhagic shock will be a candidate for surgical bleeding control. Only a few studies address the relation between the mechanism of injury and the risk of bleeding, and none of these publications is a randomised prospective trial of high evidence [52]. We have found no objective data describing the relation between the risk of bleeding and the mechanism of injury of skeletal fractures in general or of long-bone fractures in particular.

Traffic accidents are the leading cause of pelvic injury. Motor vehicle crashes cause approximately $60 \%$ of pelvic fractures followed by falls from great heights (23\%). Most of the remainder result from motorbike collisions and vehicle-pedestrian accidents [53,54]. There is a correlation between 'unstable' pelvic fractures and intraabdominal injuries [53,55]. An association between major pelvic fractures and severe head injuries, concomitant thoracic, abdominal, urological and skeletal injuries is also well described [53]. High-energy injuries produce greater damage to both the pelvis and organs. Patients with high-energy injuries require more transfusion units, and more than $75 \%$ have associated head, thorax, abdominal or genitourinary injuries [56]. It is well documented that 'unstable' pelvic fractures are associated with massive haemorrhage [55,57], and haemorrhage is the leading cause of death in patients with major pelvic fractures.

\section{Further investigation}

Recommendation 6 We recommend that patients presenting with haemorrhagic shock and an unidentified 
source of bleeding undergo immediate further investigation (Grade 1B).

Rationale A patient in haemorrhagic shock with an unidentified source of bleeding should undergo immediate further assessment of the chest, abdominal cavity and pelvic ring, which represent the major sources of acute blood loss in trauma. Aside from a clinical examination, $\mathrm{X}$-rays of chest and pelvis in conjunction with focused abdominal sonography for trauma (FAST) [58] or diagnostic peritoneal lavage (DPL) [59] are recommended diagnostic modalities during the primary survey $[37,60,61]$. In selected centres, readily available computed tomography (CT) scanners [62] may replace conventional radiographic imaging techniques during the primary survey.

\section{Imaging}

Recommendation 7 We recommend early imaging (FAST or CT) for the detection of free fluid in patients with suspected torso trauma (Grade 1B).

Recommendation 8 We recommend that patients with significant free intra-abdominal fluid and haemodynamic instability undergo urgent intervention (Grade 1A).

Recommendation 9 We recommend further assessment using CT for haemodynamically stable patients who are either suspected of having torso bleeding or have a high-risk mechanism of injury (Grade 1B).

Rationale Blunt abdominal trauma represents a major diagnostic challenge and an important source of internal bleeding. FAST has been established as a rapid and non-invasive diagnostic approach for the detection of intra-abdominal free fluid in the emergency room [63-65]. Large prospective observational studies determined a high specificity and accuracy but low sensitivity of initial FAST examination for detecting intra-abdominal injuries in adults and children [66-72]. Liu and colleagues [73] found a high sensitivity, specificity and accuracy of initial FAST examination for the detection of haemoperitoneum. Although CT scans and DPL were shown to be more sensitive than sonography for the detection of haemoperitoneum, these diagnostic modalities are more time-consuming (CT and DPL) and invasive (DPL) [73].

The role of CT scanning of acute trauma patients is well documented [74-81], and in recent years imaging for trauma patients has migrated towards multi-slice CT (MSCT). The integration of modern MSCT scanners in the emergency room area allows the immediate assessment of trauma victims following admission [76,77]. Using modern MSCT scanners, total whole-body scanning time may be reduced to less than 30 seconds. In a retrospective study comparing 370 patients in two groups, Weninger and colleagues [77] showed that faster diagnosis using MSCT led to shorter emergency room and operating room time and shorter ICU stays [77].
Huber-Wagner and colleagues [62] also showed the benefit of integration of the whole-body CT into early trauma care. CT diagnosis significantly increases the probability of survival in patients with polytrauma. Whole-body CT as a standard diagnostic tool during the earliest resuscitation phase for polytraumatised patients provides the added benefit of identifying head and chest injuries and other bleeding sources in patients with multiple injuries.

Some authors have shown the benefit of contrast medium enhanced CT scanning. Anderson and colleagues $[82,83]$ found high accuracy in the evaluation of splenic injuries resulting from trauma after administration of intravenous contrast material. Delayed phase CT may be used to detect active bleeding in solid organs. Fang and colleagues [84] demonstrated that the pooling of contrast material within the peritoneal cavity in blunt liver injuries indicates active and massive bleeding. Patients with this finding showed rapid deterioration of haemodynamic status and most of them required emergent surgery. Intraparenchymal pooling of contrast material with an unruptured liver capsule often indicates a self-limited haemorrhage, and these patients respond well to non-operative treatment.

Compared with MSCT, all traditional techniques of diagnostic and imaging evaluation are associated with some limitations. The diagnostic accuracy, safety and effectiveness of immediate MSCT are dependent on sophisticated pre-hospital treatment by trained and experienced emergency personnel and short transportation times $[85,86]$. If an MSCT is not available in the emergency room, the realisation of CT scanning implies transportation of the patient to the CT room, and therefore the clinician must evaluate the implications and potential risks and benefits of the procedure. During transport, all vital signs should be closely monitored and resuscitation measures continued. For those patients in whom haemodynamic stability is questionable, imaging techniques such as ultrasound and chest and pelvic radiography may be useful. Peritoneal lavage is rarely indicated if ultrasound or CT is available [87]. Transfer times to and from all forms of diagnostic imaging need to be considered carefully in any patient who is haemodynamically unstable. In addition to the initial clinical assessment, near patient testing results, including full blood count, haematocrit (Hct), blood gases and lactate, should be readily available under ideal circumstances.

Hypotensive patients (systolic blood pressure below $90 \mathrm{mmHg}$ ) presenting with free intra-abdominal fluid according to FAST or CT are potential candidates for early surgery if they cannot be stabilised by initiated fluid resuscitation [88-90]. A retrospective study by Rozycki and colleagues [91] of 1540 patients (1227 blunt, 313 penetrating trauma) assessed with FAST as 
an early diagnostic tool showed that the ultrasound examination had a sensitivity and specificity close to $100 \%$ when the patients were hypotensive.

A number of patients who present with free intraabdominal fluid according to FAST can safely undergo further investigation with MSCT. Under normal circumstances, adult patients need to be haemodynamically stable when MSCT is performed outside of the emergency room [91]. Haemodynamically stable patients with a high risk mechanism of injury, such as high-energy trauma or even low-energy injuries in the elderly population, should be scanned after FAST for additional injuries using MSCT. As CT scanners are integrated in resuscitation units, whole-body $\mathrm{CT}$ diagnosis may replace FAST as a diagnostic method.

\section{Haematocrit}

Recommendation 10 We do not recommend the use of single Hct measurements as an isolated laboratory marker for bleeding (Grade 1B).

Rationale Hct assays are part of the basic diagnostic work up for trauma patients. The diagnostic value of the Hct for detecting trauma patients with severe injury and occult bleeding sources has been a topic of debate in the past decade [92-94]. A major limit of the diagnostic value of Hct is the confounding influence of resuscitative measures on the Hct due to administration of intravenous fluids and red cell concentrates [94-97]. A retrospective study of 524 trauma patients determined a low sensitivity (0.5) of the initial Hct on admission for detecting those patients with traumatic haemorrhage requiring surgical intervention [94]. Two prospective observational diagnostic studies determined the sensitivity of serial Hct measurements for detecting patients with severe injury $[92,93]$. Decreasing serial Hct measurements may reflect continued bleeding, but the patient with significant bleeding may maintain his or her serial Hct.

\section{Serum lactate and base deficit}

Recommendation 11 We recommend both serum lactate and base deficit measurements as sensitive tests to estimate and monitor the extent of bleeding and shock (Grade 1B).

Rationale Serum lactate has been used as a diagnostic parameter and prognostic marker of haemorrhagic shock since the 1960s [98]. The amount of lactate produced by anaerobic glycolysis is an indirect marker of oxygen debt, tissue hypoperfusion and the severity of haemorrhagic shock [99-102]. Similarly, base deficit values derived from arterial blood gas analysis provide an indirect estimation of global tissue acidosis due to impaired perfusion $[99,101]$.

Vincent and colleagues [103] showed the value of serial lactate measurements for predicting survival in a prospective study in patients with circulatory shock.
This study showed that changes in lactate concentrations provide an early and objective evaluation of a patient's response to therapy and suggested that repeated lactate determinations represent a reliable prognostic index for patients with circulatory shock [103]. Abramson and colleagues [104] performed a prospective observational study in patients with multiple trauma to evaluate the correlation between lactate clearance and survival. All patients in whom lactate levels returned to the normal range $(\leq 2 \mathrm{mmol} / \mathrm{l})$ within 24 hours survived. Survival decreased to $77.8 \%$ if normalisation occurred within 48 hours and to $13.6 \%$ in those patients in whom lactate levels were elevated above $2 \mathrm{mmol} / \mathrm{l}$ for more than 48 hours [104]. These findings were confirmed in a study by Manikis and colleagues [105] who showed that the initial lactate levels were higher in non-survivors after major trauma, and that the prolonged time for normalisation of lactate levels of more than 24 hours was associated with the development of post-traumatic organ failure [105].

Similar to the predictive value of lactate levels, the initial base deficit has been established as a potent independent predictor of mortality in patients with traumatic hemorrhagic shock [106]. Davis and colleagues [107] stratified the extent of base deficit into three categories, mild ( -3 to $-5 \mathrm{mEq} / \mathrm{l})$, moderate $(-6$ to $-9 \mathrm{mEq} / \mathrm{l})$ and severe $(<-10 \mathrm{mEq} / \mathrm{l})$, and established a significant correlation between the admission base deficit and transfusion requirements within the first 24 hours and the risk of post-traumatic organ failure or death [107]. The same group of authors showed that the base deficit is a better prognostic marker of death than the $\mathrm{pH}$ in arterial blood gas analyses [108]. Furthermore, the base deficit was shown to represent a highly sensitive marker for the extent of post-traumatic shock and mortality, both in adult and paediatric patients [109,110].

In contrast to the data on lactate levels in haemorrhagic shock, reliable large-scale prospective studies on the correlation between base deficit and outcome are still lacking. Although both the base deficit and serum lactate levels are well correlated with shock and resuscitation, these two parameters do not strictly correlate with each other in severely injured patients [111]. Therefore, the independent assessment of both parameters is recommended for the evaluation of shock in trauma patients $[99,101,111,112]$. Composite scores that assess the likelihood of massive transfusion and include base deficit and other clinical parameters have been developed but require further validation [112,113]. Callaway and colleagues [114] performed a seven-year retrospective analysis of a prospective trauma registry from a level I trauma centre to determine predictors of mortality in elderly patients 65 years or older who sustained blunt trauma and presented with a normal initial 
systolic blood pressure ( $\geq 90 \mathrm{mmHg})$. The odds ratio for death was increased more than four-fold in those patients who had either elevated serum lactate levels above $4 \mathrm{mmol} / \mathrm{l}$ or a base deficit below $-6 \mathrm{mEq} / \mathrm{l}$, compared with patients with normal lactate levels $(<2.5 \mathrm{mmol} / \mathrm{l})$ or a base excess $(>0 \mathrm{mEq} / \mathrm{l})$. Paladino and colleagues [115] assessed the prognostic value of a combination of abnormal vital signs (heart rate $>100$ beats/ min or a systolic blood pressure $<90 \mathrm{mmHg}$ ) in conjunction with serum lactate and base deficit for identifying trauma patients with major injuries, using cut-off values for lactate at more than $2.2 \mathrm{mmol} / \mathrm{l}$ and base deficit at less than $-2.0 \mathrm{mEq} / \mathrm{l}$, respectively. The authors found that the addition of the metabolic parameters to the vital signs increased the sensitivity for identifying major injury from $40.9 \%$ to $76.4 \%$, implying that the addition of lactate and base deficit to triage vital signs increases the ability to distinguish major from minor injury.

\section{Coagulation monitoring}

Recommendation 12 We recommend that routine practice to detect post-traumatic coagulopathy include the measurement of international normalised ratio (INR), activated partial thromboplastin time (APTT), fibrinogen and platelets. INR and APTT alone should not be used to guide haemostatic therapy (Grade $1 \mathrm{C}$ ). We suggest that thrombelastometry also be performed to assist in characterising the coagulopathy and in guiding haemostatic therapy (Grade 2C).

Rationale Little evidence supports a recommendation for the best haemostatic monitoring tool(s). Standard monitoring comprises INR, APTT, platelets and fibrinogen, although there is little direct evidence for the efficacy of these measures. Increasing emphasis focuses on the importance of fibrinogen and platelet measurements.

It is often assumed that the conventional coagulation screens (INR and APTT) monitor coagulation; however, these tests monitor only the initiation phase of blood coagulation and represent only the first $4 \%$ of thrombin production [116]. It is therefore possible that the conventional coagulation screen appears normal, while the overall state of blood coagulation is abnormal. Therefore, a more complete monitoring of blood coagulation and fibrinolysis, such as thrombelastometry, may facilitate more accurate targeting of therapy. Case series using thrombelastometry to assess trauma patients have been published. One study applied thrombelastometry to 23 patients, but without a comparative standard [117]. Another study found a poor correlation between thrombelastometry and conventional coagulation parameters [10]. Johansson [118] implemented a haemostatic resuscitation regime (early platelets and fresh frozen plasma (FFP)) guided using thrombelastometry in a before-and-after study which showed improved outcomes. There is insufficient evidence at present to support the utility of thrombelastometry in the detection of post-traumatic coagulopathy. More research is required in this area, and in the meantime physicians should make their own judgement when developing local policies.

It is theoretically possible that the pattern of change in measures of coagulation such as D-dimers may help to identify patients with ongoing bleeding. However, there are no publications relevant to this question, so traditional methods of detection for ongoing bleeding, such as serial clinical evaluation of radiology (ultrasound, CT or angiography) should be used.

\section{Rapid control of bleeding}

\section{Pelvic ring closure and stabilisation}

Recommendation 13 We recommend that patients with pelvic ring disruption in haemorrhagic shock undergo immediate pelvic ring closure and stabilisation (Grade 1B).

\section{Packing, embolisation and surgery}

Recommendation 14 We recommend that patients with ongoing haemodynamic instability despite adequate pelvic ring stabilisation receive early preperitoneal packing, angiographic embolisation and/or surgical bleeding control (Grade 1B).

Rationale The mortality rate of patients with severe pelvic ring disruptions and haemodynamic instability remains unacceptably high [119-122]. The early detection of these injuries and initial efforts to reduce disruption and stabilise the pelvis as well as containing bleeding is therefore crucial. Markers of pelvic haemorrhage include anterior-posterior and vertical shear deformations, CT 'blush' (active arterial extravasation), bladder compression pressure, pelvic haematoma volumes of more than $500 \mathrm{ml}$ evident by CT and ongoing haemodynamic instability despite adequate fracture stabilisation [123-125].

The initial therapy of pelvic fractures includes control of venous and/or cancellous bone bleeding by pelvic closure. Some institutions use primarily external fixators to control haemorrhage from pelvic fractures $[124,125]$ but pelvic closure may also be achieved using a bed sheet, pelvic binder or a pelvic C-clamp [126-128]. In addition to the pelvic closure, fracture stabilisation and the tamponade effect of the haematoma, pre, extra or retroperitoneal packing will reduce or stop the venous bleeding [122,129-131]. Preperitoneal packing decreases the need for pelvic embolisation and may be performed simultaneously or soon after initial pelvic stabilisation $[122,129,131]$. The technique can be combined with a consecutive laparotomy if deemed necessary $[122,129]$. This may decrease the high mortality rate observed in patients with major pelvic injuries who underwent 
laparotomy as the primary intervention. As a consequence, it was recommended that non-therapeutic laparotomy should be avoided [132].

Angiography and embolisation is currently accepted as a highly effective means with which to control arterial bleeding that cannot be controlled by fracture stabilisation [122-126,131-140]. The presence of sacroiliac joint disruption, female gender and duration of hypotension can reliably predict patients who would benefit from the procedure [138]. Controversy exists about the indications and optimal timing of angiography in haemodynamically unstable patients [131]. Institutional differences in the capacity to perform timely angiography and embolisation may explain the different treatment algorithms suggested by many authors [119-122,125,129, $131,132,140]$. Nevertheless, the general consensus is that a multidisciplinary approach to these severe injuries is required.

\section{Early bleeding control}

Recommendation 15 We recommend that early bleeding control of the abdomen be achieved using packing, direct surgical bleeding control and the use of local haemostatic procedures. In the exsanguinating patient, aortic cross-clamping may be employed as an adjunct (Grade 1C).

Rationale Abdominal resuscitative packing is an early part of the post-traumatic laparotomy to identify major injuries and sources of haemorrhage [141,142]. If bleeding cannot be controlled using packing and conventional surgical techniques when the patient is in extremis or when proximal vascular control is deemed necessary before opening the abdomen, aortic cross clamping may be employed as an adjunct to reduce bleeding and redistribute blood flow to the heart and brain [143-145]. When blood losses are important, when surgical measures are unsuccessful and/or when the patient is cold, acidotic and coagulopathic, definitive packing may also be the first surgical step within the concept of damage control [146-155]. Packing aims to compress liver ruptures or exert direct pressure on the sources of bleeding $[141,142,146-150,152-154]$. The definitive packing of the abdomen may allow further attempts to achieve total haemostasis through angiography and/or correction of coagulopathy [155]. The removal of packs should preferably be performed only after 48 hours to lower the risk of rebleeding [152,153].

\section{Damage control surgery}

Recommendation 16 We recommend that damage control surgery be employed in the severely injured patient presenting with deep haemorrhagic shock, signs of ongoing bleeding and coagulopathy. Additional factors that should trigger a damage control approach are hypothermia, acidosis, inaccessible major anatomical injury, a need for time-consuming procedures or concomitant major injury outside the abdomen (Grade 1C).

Rationale The severely injured patient arriving to the hospital with continuous bleeding or deep haemorrhagic shock generally has a poor chance of survival unless early control of bleeding, proper resuscitation and blood transfusion are achieved. This is particularly true for patients who present with uncontrolled bleeding due to multiple penetrating injuries or patients with multiple injuries and unstable pelvic fractures with ongoing bleeding from fracture sites and retroperitoneal vessels. The common denominator in these patients is the exhaustion of physiological reserves with resulting profound acidosis, hypothermia and coagulopathy, also known as the 'bloody vicious cycle'. In 1983, Stone and colleagues described the techniques of abbreviated laparotomy, packing to control haemorrhage and of deferred definitive surgical repair until coagulation has been established [156]. Since then, a number of authors have described the beneficial results of this concept, now called 'damage control' [50,54,121,134,151,156-158]. Damage control surgery of the abdomen consists of three components: the first component is an abbreviated resuscitative laparotomy for control of bleeding, the restitution of blood flow where necessary and the control of contamination. This should be achieved as rapidly as possible without spending unnecessary time on traditional organ repairs that can be deferred to a later phase. The abdomen is packed and temporary abdominal closure is performed. The second component is intensive care treatment, focused on core re-warming, correction of the acid-base imbalance and coagulopathy as well as optimising the ventilation and the haemodynamic status. The third component is the definitive surgical repair that is performed only when target parameters have been achieved [159-162]. Although the concept of 'damage control' intuitively makes sense, no RCTs exist to support it. Retrospective studies support the concept showing reduced morbidity and mortality rates in selective populations $[50,151,157,161]$.

The same 'damage control' principles have been applied to orthopaedic injuries in severely injured patients [134,163-166]. Scalea was the first to coin the term 'damage control orthopaedics' [166]. Relevant fractures are primarily stabilised with external fixators rather than primary definitive osteosynthesis $[134,163]$. The less traumatic and shorter duration of the surgical procedure aims to reduce the secondary trauma load. Definitive osteosynthesis surgery can be performed after 4 to 14 days when the patient has recovered sufficiently. Retrospective clinical studies and prospective cohort studies seem to support the concept of damage control [134,163-165]. The only available randomised study 
shows an advantage for this strategy in 'borderline' patients [164].

\section{Local haemostatic measures}

Recommendation 17 We recommend the use of topical haemostatic agents in combination with other surgical measures or with packing for venous or moderate arterial bleeding associated with parenchymal injuries (Grade 1B).

Rationale A wide range of local haemostatic agents are currently available for use as adjuncts to traditional surgical techniques to obtain haemorrhage control. These topical agents can be particularly useful when access to the bleeding area is difficult. Local haemostatic agents include collagen, gelatin or cellulosebased products, fibrin and synthetic glues or adhesives that can be used for both external and internal bleeding while polysaccharide-based and inorganic haemostatics are still mainly used and approved for external bleeding. The use of topical haemostatic agents should consider several factors such as the type of surgical procedure, cost, severity of bleeding, coagulation status and each agent's specific characteristics. Some of these agents should be avoided when autotransfusion is used and several other contraindications need to be considered $[167,168]$. The capacity of each agent to control bleeding was initially studied in animals but increasing experience from humans is now available [167-180].

The different types of local haemostatics are briefly presented according to their basis and haemostatic capacity:

i) Collagen-based agents trigger platelet aggregation resulting in clot formation when in contact with a bleeding surface. They are often combined with a procoagulant substance such as thrombin to enhance the haemostatic effect. A positive haemostatic effect has been shown in several human studies [169-172].

ii) Gelatin-based products can be used alone or in combination with a procoagulant substance [167]. Swelling of the gelatin in contact with blood reduces the blood flow and, in combination with a thrombin-based component, enhances haemostasis. A similar or superior haemostatic effect has been observed compared with collagen-based agents [173-175].

iii) The effect of cellulose-based haemostatic agents on bleeding has been less well studied and only case reports that support their use are available.

iv) Fibrin and synthetic glues or adhesives have both haemostatic and sealant properties and their significant effect on haemostasis have been shown in several human RCTs involving vascular, bone, skin and visceral surgery [176-178].

v) Polysaccharide-based haemostatics can be divided into two broad categories [167]: N-acetyl-glucosaminecontaining glycosaminoglycans purified from microalgae and diatoms and microporous polysaccharide haemospheres produced from potato starch. The mechanism of action is complex and depends on the purity or combination with other substances such as cellulose or fibrin. A number of different products are currently available and have been shown to be efficient for external use. An observational study showed that haemorrhage control was achieved using an $\mathrm{N}$-acetylglucosamine-based bandage applied to 10 patients with severe hepatic and abdominal injuries, acidosis and clinical coagulopathy [180].

vi) The inorganic haemostatics based on minerals such as zeolite or smectite have been used and studied mainly on external bleeding $[167,168]$.

\section{Tissue oxygenation, fluid and hypothermia Volume replacement}

Recommendation 18 We recommend a target systolic blood pressure of 80 to $100 \mathrm{mmHg}$ until major bleeding has been stopped in the initial phase following trauma without brain injury (Grade 1C).

Rationale In order to maintain tissue oxygenation, traditional treatment of trauma patients uses early and aggressive fluid administration to restore blood volume. This approach may, however, increase the hydrostatic pressure on the wound, cause a dislodgement of blood clots, a dilution of coagulation factors and undesirable cooling of the patient. The concept of low-volume fluid resuscitation, so-called 'permissive hypotension', avoids the adverse effects of early aggressive resuscitation while maintaining a level of tissue perfusion that, although lower than normal, is adequate for short periods [130]. A controlled hypotensive fluid resuscitation should aim to achieve a mean arterial pressure of $65 \mathrm{mmHg}$ or more [181]. Its general effectiveness remains to be confirmed in RCTs; however, studies have demonstrated increased survival when a low volume fluid resuscitation concept was used in penetrating trauma [182,183]. In contrast, no significant difference in survival was found in patients with blunt trauma [184]. One study concluded that mortality was higher after on-site resuscitation compared with in-hospital resuscitation [185]. It seems that greater increases in blood pressure are tolerated without exacerbating haemorrhage when they are achieved gradually and with a significant delay following the initial injury [186]. All the same, a recent Cochrane systematic review concluded that there is no evidence from RCTs for or against early or larger volume intravenous fluids to treat uncontrolled haemorrhage [187]. However, a recent retrospective analysis demonstrated that aggressive resuscitation techniques, often initiated in the prehospital setting, appear to increase the likelihood that patients with severe extremity injuries develop secondary abdominal compartment syndrome (ACS) 
[188]. In this study, early, large-volume crystalloid administration was the greatest predictor of secondary ACS. Moreover, a retrospective analysis of the German Trauma Registry database including 17,200 multiply injured patients showed that the incidence of coagulopathy increased with increasing volume of intravenous fluids administered pre-clinically. Coagulopathy was observed in more than $40 \%$ of patients with more than $2000 \mathrm{ml}$, in more than $50 \%$ with more than $3000 \mathrm{ml}$, and in more than $70 \%$ with more than $4000 \mathrm{ml}$ administered [3].

The low-volume approach is contraindicated in TBI and spinal injuries, because an adequate perfusion pressure is crucial to ensure tissue oxygenation of the injured central nervous system. In addition, the concept of permissive hypotension should be carefully considered in the elderly patient and may be contraindicated if the patient suffers from chronic arterial hypertension.

A recent analysis from an ongoing multi-centre prospective cohort study suggests that the early use of vasopressors for haemodynamic support after haemorrhagic shock in comparison to aggressive volume resuscitation may be deleterious and should be used cautiously [189]. However, this study has several limitations: the study is a secondary analysis of a prospective cohort study, and was not designed to answer the specific hypothesis tested. Thus, it is not possible to separate vasopressor from the early management of trauma patients. In addition, although the use of a vasopressor helps to rapidly restore arterial pressure, it should not be viewed as a substitute for fluid resuscitation and the target blood pressure must be respected.

\section{Fluid therapy}

Recommendation 19 We recommend that crystalloids be applied initially to treat the bleeding trauma patient (Grade 1B). We suggest that hypertonic solutions also be considered during initial treatment (Grade 2B). We suggest that the addition of colloids be considered within the prescribed limits for each solution in haemodynamically unstable patients (Grade 2C).

Rationale It is still unclear what type of fluid should be employed in the initial treatment of the bleeding trauma patient. Although several meta-analyses have shown an increased risk of death in patients treated with colloids compared with patients treated with crystalloids [190-194] and three of these studies showed that the effect was particularly significant in a trauma subgroup $[190,193,194]$, a more recent meta-analysis showed no difference in mortality between colloids and crystalloids [195]. If colloids are used, modern hydroxyethyl starch or gelatin solutions should be used because the risk:benefit ratio of dextran is disadvantageous. Problems in evaluating and comparing the use of different resuscitation fluids include the heterogeneity of populations and therapy strategies, limited quality of analysed studies, mortality not always being the primary outcome, and different, often short, observation periods. It is therefore difficult to reach a definitive conclusion as to the advantage of one type of resuscitation fluid over the other. The Saline versus Albumin Fluid Evaluation study compared $4 \%$ albumin with $0.9 \%$ sodium chloride in 6997 ICU patients and showed that albumin administration was not associated with worse outcomes; however, there was a trend towards higher mortality in the brain trauma subgroup that received albumin $(P=0.06)$ [196]. Promising results have been obtained with hypertonic solutions. Recently, a double-blind, RCT in 209 patients with blunt traumatic injuries analysed the effect of the treatment with $250 \mathrm{ml}$ of $7.5 \%$ hypertonic saline and 6\% dextran 70 compared with lactated Ringer solution on organ failure. The intent-to-treat analysis demonstrated no significant difference in organ failure and in acute respiratory disress syndrome (ARDS)-free survival. However, there was improved ARDS-free survival in the subset (19\% of the population) requiring $10 \mathrm{U}$ or more of packed red blood cells (RBCs) [197]. One study showed that the use of hypertonic saline was associated with lower intracranial pressure than with normal saline in brain-injured patients [198] and a meta-analysis comparing hypertonic saline dextran with normal saline for resuscitation in hypotension from penetrating torso injuries showed improved survival in the hypertonic saline dextran group when surgery was required [199]. A clinical trial with brain injury patients found that hypertonic saline reduced intracranial pressure more effectively than dextran solution with $20 \%$ mannitol when compared in equimolar dosing [200]. However, Cooper and colleagues found almost no difference in neurological function six months after TBI in patients who had received pre-hospital hypertonic saline resuscitation compared with conventional fluid [201]. In conclusion, the evidence suggests that hypertonic saline solutions are safe, and will improve haemodynamics during hypovolaemic resuscitation. The evidence for increased survival with use of hypertonic saline solutions is inconclusive. It is possible that certain subgroups might benefit from hypertonic saline solutions, but further research is required [202].

\section{Normothermia}

Recommendation 20 We recommend early application of measures to reduce heat loss and warm the hypothermic patient in order to achieve and maintain normothermia (Grade 1C).

Rationale Hypothermia, defined as a core body temperature below $35^{\circ} \mathrm{C}$, is associated with acidosis, hypotension and coagulopathy in severely injured patients. In a retrospective study with 122 patients, hypothermia was an ominous clinical sign, accompanied by high 
mortality and blood loss [203]. The profound clinical effects of hypothermia ultimately lead to higher morbidity and mortality, and hypothermic patients require more blood products [204].

Hypothermia is associated with an increased risk of severe bleeding, and hypothermia in trauma patients represents an independent risk factor for bleeding and death [205]. The effects of hypothermia include altered platelet function, impaired coagulation factor function (a $1^{\circ} \mathrm{C}$ drop in temperature is associated with a $10 \%$ drop in function), enzyme inhibition and fibrinolysis $[206,207]$. Body temperatures below $34^{\circ} \mathrm{C}$ compromise blood coagulation, but this has only been observed when coagulation tests (prothrombin time (PT) and APTT) are carried out at the low temperatures seen in patients with hypothermia, and not when assessed at $37^{\circ} \mathrm{C}$ as is routine practice for such tests. Steps to prevent hypothermia and the risk of hypothermia-induced coagulopathy include removing wet clothing, covering the patient to avoid additional heat loss, increasing the ambient temperature, forced air warming, warm fluid therapy and, in extreme cases, extracorporeal re-warming devices [208,209].

Animal and human studies of controlled hypothermia in haemorrhage have shown some positive results compared with normothermia [210,211]. Contradictory results have been observed in meta-analyses that examine mortality and neurological outcomes associated with mild hypothermia in patients with TBI, possibly due to the different exclusion and inclusion criteria for the studies used for the analysis [212-214]. The speed of induction and duration of hypothermia, which may be very important factors that influence the benefit associated with this treatment. It has been shown that five days of long-term cooling is more efficacious than two days of short-term cooling when mild hypothermia is used to control refractory intracranial hypertension in adults with severe TBI [215]. Obviously, the time span of hypothermia is crucial, because a recent prospective RCT in 225 children with severe TBI showed that hypothermic therapy initiated within 8 hours after injury and continued for 24 hours did not improve the neurological outcome and may increase mortality [216]. Furthermore, the mode of inducing cerebral hypothermia induction may influence its effectiveness. In a RCT comparing non-invasive selective brain cooling $\left(33\right.$ to $35^{\circ} \mathrm{C}$ ) in 66 patients with severe TBI and mild systemic hypothermia (rectal temperature 33 to $35^{\circ} \mathrm{C}$ ) and a control group not exposed to hypothermia, natural rewarming began after three days. Mean intracranial pressure 24, 48 or 72 hours after injury was significantly lower in the selective brain cooling group than in the control group [217].

Prolonged hypothermia may be considered in patients with isolated head trauma after haemorrhage has been arrested. If mild hypothermia is applied in TBI, cooling should take place within the first three hours following injury, preferably using selective brain cooling by cooling the head and neck, be maintained for at least 48 hours [218], rewarming should last 24 hours and the cerebral perfusion pressure should be maintained above $50 \mathrm{mmHg}$ (systolic blood pressure $\geq 70 \mathrm{mmHg}$ ). Patients most likely to benefit from hypothermia are those with a GCS at admission between 4 and 7 [219]. Possible side effects are hypotension, hypovolaemia, electrolyte disorders, insulin resistance and reduced insulin secretion and increased risk of infection [220]. Further studies are warranted to investigate the postulated benefit of hypothermia in TBI taking these important factors into account.

\section{Management of bleeding and coagulation Erythrocytes}

Recommendation 21 We recommend a target haemoglobin (Hb) of 7 to $9 \mathrm{~g} / \mathrm{dl}$ (Grade 1C).

Rationale Erythrocytes contribute to haemostasis by influencing the biochemical and functional responsiveness of activated platelets via the rheological effect on platelet margination and by supporting thrombin generation [221]; however, the optimal Hct or Hb concentration required to sustain haemostasis in massively bleeding patients is unclear. Further investigations into the role of the $\mathrm{Hb}$ concentration on haemostasis in massively transfused patients are therefore warranted.

The effects of the Hct on blood coagulation have not been fully elucidated [222]. An acute reduction of the Hct results in an increase in the bleeding time [223,224] with restoration upon re-transfusion [223]. This may relate to the presence of the enzyme elastase on the surface of RBC membranes, which may activate coagulation factor IX $[225,226]$. However, a moderate reduction of the Hct does not increase blood loss from a standard spleen injury [224], and an isolated in vitro reduction of the Hct did not compromise blood coagulation as assessed by thrombelastometry [227].

No prospective RCT has compared restrictive and liberal transfusion regimens in trauma, but 203 trauma patients from the Transfusion Requirements in Critical Care trial [228] were re-analysed [229]. A restrictive transfusion regimen $(\mathrm{Hb}$ transfusion trigger $<7.0 \mathrm{~g} / \mathrm{dl})$ resulted in fewer transfusions as compared with the liberal transfusion regimen $(\mathrm{Hb}$ transfusion trigger $<10 \mathrm{~g} / \mathrm{dl})$ and appeared to be safe. However, no statistically significant benefit in terms of multiple organ failure or post-traumatic infections was observed. It should be emphasised that this study was neither designed nor powered to answer these questions with precision. In addition, it cannot be ruled out that the number of RBC units transfused merely reflects the severity of injury. Nevertheless, RBC transfusions have been 
shown in multiple studies to be associated with increased mortality [230-234], lung injury [234-236], increased infection rates $[237,238]$ and renal failure in trauma victims [233]. This ill effect may be particularly important with RBC transfusions stored for more than 14 days [233].

Despite the lack of high-level scientific evidence for a specific $\mathrm{Hb}$ transfusion trigger in patients with TBI, these patients are currently transfused in many centres to achieve an $\mathrm{Hb}$ of approximately $10 \mathrm{~g} / \mathrm{dl}$ [239]. This might be justified by the recent finding that increasing the $\mathrm{Hb}$ from 8.7 to $10.2 \mathrm{~g} / \mathrm{dl}$ improved local cerebral oxygenation in $75 \%$ of patients [158]. In another preliminary study in patients with TBI, one to two RBC transfusions at a $\mathrm{Hb}$ of approximately $9 \mathrm{~g} / \mathrm{dl}$ transiently (three to six hours) increased cerebral oxygenation, again in approximately $75 \%$ of patients $[240,241]$. A storage time of more than 19 days precluded this effect [240]. In another recent study, cerebral tissue oxygenation, on average, did not increase due to an increase in $\mathrm{Hb}$ from 8.2 to $10.1 \mathrm{~g} / \mathrm{dl}$ [242]. Nevertheless, the authors came to the conclusion based on multivariable statistical models that the changes in cerebral oxygenation correlated significantly with $\mathrm{Hb}$ concentration [242]. This conclusion, however, was questioned in the accompanying editorial [243].

In an initial outcome study the lowest Hct was correlated with adverse neurological outcome and RBC transfusions were also found to be an independent factor predicting adverse neurological outcome [244]. Interestingly, the number of days with a Hct below $30 \%$ was found to be correlated with an improved neurological outcome [244]. In a more recent outcome study in 1150 patients with TBI, RBC transfusions were found to be associated with a two-fold increased mortality and a three-fold increased complication rate [138]. Therefore, patients with severe TBI should not have an $\mathrm{Hb}$ transfusion threshold different than that of other critically ill patients.

\section{Coagulation support}

Recommendation 22 We recommend that monitoring and measures to support coagulation be initiated as early as possible (Grade 1C).

Rationale Major trauma results not only in bleeding from anatomical sites but also frequently in coagulopathy, which is associated with a several-fold increase in mortality $[3,5,8,9,245]$. This early coagulopathy of trauma is mainly found in patients with hypoperfusion (base deficit $>6 \mathrm{mE} / \mathrm{l}$ ) $[8,245]$ and is characterised by an up-regulation of endothelial thrombomodulin, which forms complexes with thrombin [246].

Early monitoring of coagulation is essential to detect trauma-induced coagulopathy and to define the main causes, including hyperfibrinolysis [10,117]. Early therapeutic intervention does improve coagulation tests [247] and persistent coagulopathy at ICU entry has been shown to be associated with a increased mortality [248]. Therefore, early aggressive treatment is likely to improve the outcome of severely injured patients [249]. However, there are also studies in which no survival benefit could be shown $[247,250]$.

\section{Calcium}

Recommendation 23 We recommend that ionised calcium levels be monitored during massive transfusion (Grade 1C). We suggest that calcium chloride be administered during massive transfusion if ionised calcium levels are low or electrocardiographic changes suggest hypocalcaemia (Grade 2C).

Rationale Calcium in the extracellular plasma exists either in a free ionised state (45\%) or bound to proteins and other molecules in a biologically inactive state (55\%). The normal concentration of the ionised form ranges from 1.1 to $1.3 \mathrm{mmol} / \mathrm{l}$ and is influenced by the $\mathrm{pH}$. A 0.1 unit increase in $\mathrm{pH}$ decreases the ionised calcium concentration by approximately $0.05 \mathrm{mmol} / \mathrm{l}$ [181]. The availability of ionised calcium is essential for the timely formation and stabilisation of fibrin polymerisation sites, and a decrease in cytosolic calcium concentration precipitates a decrease in all platelet-related activities [181]. In addition, contractility of the heart and systemic vascular resistance are compromised at low ionised calcium levels. Combining beneficial cardiovascular and coagulation effects, the level for ionised calcium concentration should therefore be maintained above $0.9 \mathrm{mmol} / \mathrm{l}$ [181].

Early hypocalcaemia following traumatic injury shows a significant correlation with the amount of infused colloids, but not with crystalloids, and may be attributable to colloid-induced haemodilution [251]. Also, hypocalcaemia develops during massive transfusion as a result of the citrate employed as an anticoagulant in blood products. Citrate exerts its anticoagulant activity by binding ionised calcium, and hypocalcaemia is most common in association with FFP and platelet transfusion because these products contain high citrate concentrations. Citrate undergoes rapid hepatic metabolism, and hypocalcaemia is generally transient during standard transfusion procedures. Citrate metabolism may be dramatically impaired by hypoperfusion states, hypothermia and in patients with hepatic insufficiency [252].

\section{Fresh frozen plasma}

Recommendation 24 We recommend early treatment with thawed FFP in patients with massive bleeding (Grade 1B). The initial recommended dose is 10 to $15 \mathrm{ml} / \mathrm{kg}$. Further doses will depend on coagulation monitoring and the amount of other blood products administered (Grade 1C).

Rationale The clinical efficacy of FFP is largely unproven [253]. Nevertheless, most guidelines recommend the 
use of FFP either in massive bleeding or in significant bleeding complicated by coagulopathy (PT or APTT more than 1.5 times control) $[7,254,255]$. Patients treated with oral anticoagulants (vitamin $\mathrm{K}$ antagonists) present a particular challenge, and FFP is recommended [255] only when prothrombin complex concentrate (PCC) is not available [254]. The most frequently recommended dose is 10 to $15 \mathrm{ml} / \mathrm{kg}$ [254,255], and further doses may be required [256]. As with all products derived from human blood, the risks associated with FFP treatment include circulatory overload, ABO incompatibility, transmission of infectious diseases (including prion diseases), mild allergic reactions and transfusion-related acute lung injury $[254,257,258]$. FFP and platelet concentrates appear to be the most frequently implicated blood products in transfusion-related acute lung injury [257-260]. Although the formal link between the administration of FFP, control of bleeding and an eventual improvement in the outcome of bleeding patients is lacking, most experts would agree that FFP treatment is beneficial in patients with massive bleeding or significant bleeding complicated by coagulopathy.

There are very few well-designed studies that explore massive transfusion strategy. The need for massive transfusion is relatively rare, occurring in less than $2 \%$ of civilian trauma patients, but higher (7\%) in the military setting. Massive transfusion management has been based on the concept that coagulopathy associated with severe trauma was primarily consumptive due to the dilution of blood clotting factors and the consumption of haemostasis factors at the site of injury.

FFP was recommended when PT or APTT was 1.5 times normal or after $10 \mathrm{RBC}$ units had been transfused. Many massive transfusion protocols stipulated one unit of FFP for every four units of RBCs. In recent years, retrospective data from the US Army combat support hospitals have shown an association between survival and a higher ratio of transfused FFP and RBC units. These data show that casualties who received FFP and RBCs at a ratio of 1:4 or lower, had a three-fold higher mortality than those who received a massive transfusion with a $2: 3$ ratio. These data have induced many civilian trauma centres to modify their transfusion approach to incorporate the early use of thawed FFP in ratios approaching 1:1.

Ten relevant studies addressing FFP:RBC ratio have been identified, all of which were retrospective studies, although some are based on data collected prospectively for other reasons. None of the studies were clinical RCTs. The majority of the authors used massive transfusion (10 RBC units within 24 hours) as the entry criterion; however, to limit bias due to FFP unavailability, one study [261] excluded patients who died within the first 30 minutes. One of the studies [262] took into consideration only patients alive upon ICU admission, and another defined massive transfusion as 10 units or more prior to ICU admission. One report [247] defined massive transfusion as more than 10 units over 6 hours. Two of the studies are based on data collected in a combat setting, while the other eight were performed based on data collected at civilian trauma centres. The majority of the studies are single centre; one study is multi-centre [261] and one is a retrospective analysis of the German Trauma Registry [3].

Seven studies showed better outcomes using a high FFP:RBC ratio [3,261-266] and two did not [250,267]. One study may be classified as indeterminate because a high FFP:RBC ratio (average 1:2) was associated with a better survival than a low ratio (average 1:4), but the survival curve was U-shaped, with the lowest mortality at a $1: 2$ to $1: 3$ ratio [247]. The two combat studies showed better outcomes using a high ratio $[265,266]$. Early empirical infusion of FFP may increase the frequency of delayed traumatic intracerebral haematoma and the mortality in patients with severe head injury [268]. Most of the studies calculate FFP:RBC ratio at 24 hours after admission. When Snyder and colleagues [267] used the FFP:RBC ratio at 24 hours as a fixed value, patients who received a higher ratio had significantly better outcomes, but if the timing of component product transfusion was taken into account, the difference was no longer statistically significant.

These combat data are retrospective, refer to young, previously healthy male patients with penetrating injuries and may be confounded to some extent by treatment biases. Because FFP requires a significant amount of time before it is thawed and available for transfusion and many trauma deaths occur soon after hospital admission, patients who die early may receive $\mathrm{RBC}$ units but die before FFP therapy has begun. These cases may therefore be included in the low ratio group even if a 1:1 strategy was intended. One further ground for criticism of many of these studies is that the number of RBCs units transfused is an indicator of severity of injury that cannot be completely adjusted for by regression analysis. All of these limitations must be kept in mind when analysing the available recent literature and emphasises the need for prospective trials.

Platelets

Recommendation 25 We recommend that platelets be administered to maintain a platelet count above $50 \times$ $10^{9} / 1$ (Grade 1C). We suggest maintenance of a platelet count above $100 \times 10^{9} / 1$ in patients with multiple trauma who are severely bleeding or have TBI (Grade $2 \mathrm{C})$. We suggest an initial dose of four to eight platelet concentrates or one aphaeresis pack (Grade 2C).

Rationale In medical conditions leading to thrombocytopaenia, haemorrhage does not often occur until the 
platelet count falls below $50 \times 10^{9} / \mathrm{l}$, and platelet function decreases exponentially below this point [269-272]. There is no direct evidence to support a particular platelet transfusion threshold in the trauma patient. A consensus development conference sponsored by the National Institutes of Health (NIH; Bethesda, MD, USA) in 1986 determined that bleeding is unlikely to be caused by thrombocytopaenia at platelet counts of $50 \times$ $10^{9} / 1$ or greater and agreed that platelet transfusion is appropriate to prevent or control bleeding associated with deficiencies in platelet number or function $[273,274]$. The NIH consensus did not consider trauma, but it seems reasonable to recommend that a platelet count of at least $50 \times 10^{9} / 1$ be maintained following injury.

An argument can be made for maintaining a higher level of platelets, perhaps up to $100 \times 10^{9} / 1$, following injury. If a patient has increased fibrin degradation products due to disseminated intravascular coagulation and/or hyperfibrinolysis, this will interfere with platelet function and a higher threshold of $75 \times 10^{9} / 1$ has been suggested by consensus groups [275,276]. Moreover, platelet-rich concentrate is an autologous concentration of platelets and growth factors (e.g. transforming growth factor-beta, vascular endothelial growth factor and platelet-derived growth factor), and due to the increased concentration and release of these factors, platelet-rich concentrates could potentially enhance bone and soft tissue healing [277]. Transfusion threshold levels of up to $100 \times 10^{9} / 1$ have been suggested for treatment of severe brain injury and massive haemorrhage, but the evidence for the higher threshold is weak [275,276]. One group showed that trauma patients receiving platelets and $\mathrm{RBCs}$ at a ratio of 1:5 or greater had a lower 30-day mortality when compared with those with who received less than this ratio ( $38 \%$ vs. $61 \%, P=0.001)$ [264]. Another study of massively transfused trauma patients has pointed to an early aggressive correction of coagulopathy with platelet transfusion as a possible contributing factor to good outcome [278]. In this retrospective cohort study, survivors received one platelet transfusion for every 7.7 units of blood transfused whereas nonsurvivors received only one platelet transfusion for every 11.9 units of blood transfused $(P=0.03)$.

When platelet transfusion was introduced in the 1950s, no clinical trials were employed to assess the utility of platelet therapy compared with placebo, and such trials today might be considered unethical. The appropriate dose of platelets is therefore uncertain. Platelet concentrate produced from a unit of whole blood contains $7.5 \times 10^{10}$ platelets on average and should increase the platelet count by 5 to $10 \times 10^{9} / \mathrm{l}$ in a $70 \mathrm{~kg}$ recipient. Aphaeresis platelet concentrates generally contain approximately 3 to $6 \times 10^{11}$ platelets, depending on local collection practice, and physicians should be cognisant of the doses provided locally. A pool of four to eight platelet concentrates or a single-donor aphaeresis unit is usually sufficient to provide haemostasis in a thrombocytopaenic, bleeding patient. If required, the dose of platelets $\left(\times 10^{9}\right)$ can be calculated in more detail from the desired platelet increment, the patient's blood volume in litres (estimated by multiplying the patient's body surface area by 2.5 , or $70 \mathrm{ml} / \mathrm{kg}$ in an adult), and a correction factor of 0.67 to allow for pooling of approximately 33\% of transfused platelets in the spleen.

\section{Fibrinogen and cryoprecipitate}

Recommendation 26 We recommend treatment with fibrinogen concentrate or cryoprecipitate if significant bleeding is accompanied by thrombelastometric signs of a functional fibrinogen deficit or a plasma fibrinogen level of less than 1.5 to $2.0 \mathrm{~g} / \mathrm{l}$ (Grade $1 \mathrm{C}$ ). We suggest an initial fibrinogen concentrate dose of 3 to $4 \mathrm{~g}$ or $50 \mathrm{mg} / \mathrm{kg}$ of cryoprecipitate, which is approximately equivalent to 15 to 20 units in a $70 \mathrm{~kg}$ adult. Repeat doses may be guided by thrombelastometric monitoring and laboratory assessment of fibrinogen levels (Grade 2C).

Rationale The formation of fibrin is a key step in blood coagulation [222,279], and hypofibrinogenemia is a usual component of complex coagulopathies associated with massive bleeding. Coagulopathic civilian trauma patients had a fibrinogen concentration of $0.9 \mathrm{~g} / \mathrm{l}$ (interquartile ratio (IQR) 0.5 to $1.5 \mathrm{~g} / \mathrm{l}$ ) in conjunction with a maximum clot firmness of $6 \mathrm{~mm}$ (IQR 0 to $9 \mathrm{~mm}$ ) using thrombelastometry, whereas only $2.5 \%$ of healthy volunteers had a maximum clot firmness of $7 \mathrm{~mm}$ or less [10]. In trauma patients, a maximum clot firmness of $7 \mathrm{~mm}$ was associated with a fibrinogen level of approximately $2 \mathrm{~g} / \mathrm{l}$ [10]. During massive blood loss replacement, fibrinogen may be the first coagulation factor to decrease critically [280]. During postpartum haemorrhage, fibrinogen plasma concentration is the only coagulation parameter independently associated with progress toward severe bleeding, with a level less than $2 \mathrm{~g} / \mathrm{l}$ having a positive predictive value of $100 \%$ [281]. Blood loss and blood transfusion needs were also found to inversely correlate with preoperative fibrinogen levels in coronary artery bypass graft surgery [282].

During serious perioperative bleeding, fibrinogen treatment ( $2 \mathrm{~g}$, range 1 to $5 \mathrm{~g}$ ) was associated with a reduction in allogeneic blood product transfusion [283]. The fibrinogen concentration before treatment was $1.4 \mathrm{~g} / \mathrm{l}$ (IQR 1.0 to $1.8 \mathrm{~g} / \mathrm{l}$ ) rising to $2.4 \mathrm{~g} / \mathrm{l}$ (IQR 2.1 to $2.6 \mathrm{~g} / \mathrm{l})$ after fibrinogen substitution [283]. An observational study suggests that fibrinogen substitution can improve survival in combat-related trauma [284]. An RCT in patients undergoing radical cystectomy with excessive blood loss has shown that postoperative blood 
transfusions could be reduced by the administration of $45 \mathrm{mg} / \mathrm{kg}$ fibrinogen at a mean pre-treatment fibrinogen level of $1.7 \pm 0.3 \mathrm{~g} / \mathrm{l}$ rising to $2.4 \pm 0.1 \mathrm{~g} / \mathrm{l}$ following fibrinogen substitution [285].

Fibrinogen administration using thrombelastometry as guidance may be preferable to measuring fibrinogen levels in the laboratory. Some methodological issues in the various laboratory methods to measure fibrinogen concentration remain [286,287], and in the presence of artificial colloids such as hydroxyethyl starch, even the most frequently recommended method [287], the Clauss method, significantly overestimates the actual fibrinogen concentration [288].

It is not known whether the administration of fibrinogen via factor concentrate, cryoprecipitate or FFP is associated with a post-traumatic venous thrombotic risk. However, fibrinogen levels are expected to rise to a level of approximately $7 \mathrm{~g} / \mathrm{l}$ after major surgery and trauma $[289,290]$ even without intra-operative fibrinogen administration, and the effect of intra-operative fibrinogen administration on postoperative fibrinogen levels is unknown at the present time. Interestingly, intra-operative administration of $45 \mathrm{mg} / \mathrm{kg}$ fibrinogen concentrate in patients undergoing cystectomy resulted in higher early postoperative fibrinogen levels but already at 24 hours post-operation fibrinogen levels were identical in patients with and without intra-operative fibrinogen administration [285]. Similarly, 24 hour fibrinogen levels were identical in patients who received and those who did not receive $2 \mathrm{~g}$ of fibrinogen prior to coronary artery bypass graft surgery [291]. This result is in keeping with the study by Weinkove and Rangarajan, who found no thrombotic risk in patients treated with fibrinogen concentrate due to acquired hypofibrinogenemia (fibrinogen $<1.5 \mathrm{~g} / \mathrm{l})$ [292].

\section{Pharmacological agents}

An increasingly large body of evidence supports the use of antifibrinolytic agents for the management of bleeding in elective surgery and cardiac surgery patients. For the purpose of these guidelines, we have assumed that these effects are transferable to trauma patients, and our recommendations are based upon this unproven assumption. Since the last guidelines were written, aprotinin has been associated with patient safety issues, with an increased rate of renal disease and mortality when compared with the lysine analogues in a large clinical trial and is therefore no longer recommended [293-296].

\section{Antifibrinolytic agents}

Recommendation 27 We suggest that antifibrinolytic agents be considered in the bleeding trauma patient (Grade 2C). We recommend monitoring of fibrinolysis in all patients and administration of antifibrinolytic agents in patients with established hyperfibrinolysis (Grade 1B). Suggested dosages are tranexamic acid 10 to
$15 \mathrm{mg} / \mathrm{kg}$ followed by an infusion of 1 to $5 \mathrm{mg} / \mathrm{kg}$ per hour or $\varepsilon$-aminocaproic acid 100 to $150 \mathrm{mg} / \mathrm{kg}$ followed by $15 \mathrm{mg} / \mathrm{kg} / \mathrm{h}$. Antifibrinolytic therapy should be guided by thrombelastometric monitoring if possible and stopped once bleeding has been adequately controlled (Grade 2C).

Rationale Tranexamic acid (trans-4-aminomethylcyclohexane-1-carboxylic acid) is a synthetic lysine analogue that is a competitive inhibitor of plasmin and plasminogen. Tranexamic acid is distributed throughout all tissues and the plasma half-life is 120 minutes. There is large variation in the dose employed. In vitro studies have suggested that a dose of $10 \mu \mathrm{g} / \mathrm{ml}$ is required to inhibit fibrinolysis [297]. Studies of plasma levels [298] confirmed that the Horrow regimen $(10 \mathrm{mg} / \mathrm{kg}$ followed by $1 \mathrm{mg} / \mathrm{kg}$ per hour) [299], shown to reduce blood loss in cardiac surgery, attained these levels. Other studies have used boluses of up to $5 \mathrm{~g}$ per patient with no ill effect [300].

$\varepsilon$-aminocaproic acid is also a synthetic lysine analogue that has a potency 10 -fold weaker than that of tranexamic acid. It is therefore administered in a loading dose of $150 \mathrm{mg} / \mathrm{kg}$ followed by a continuous infusion of $15 \mathrm{mg} / \mathrm{kg} / \mathrm{h}$. The initial elimination half-life is 60 to 75 minutes and it must therefore be administered by continuous infusion in order to maintain therapeutic drug levels until the bleeding risk has diminished.

The clear efficacy of antifibrinolytic agents in reducing bleeding in elective surgery and especially in cardiac surgery has been shown in numerous clinical trials [301-305]. The benefits of antifibrinolytics in these situations where hyperfibrinolysis is not usually seen, suggests that under normal circumstances when a patient has a bleeding vessel, there is low-grade fibrinolytic turnover that exacerbates bleeding. Thus, fibrinolysis is 'switched off' and less bleeding results. It may be possible to extrapolate the benefits of antifibrinolytic agents to bleeding secondary to trauma, although this assumption is not backed by any published data that suggest that the haemostatic response to trauma is similar to the haemostatic response to elective surgery. There is insufficient evidence from RCTs of antifibrinolytic agents in trauma patients to either support or refute a clinically important treatment effect. The efficacy of tranexamic acid in trauma has been assessed by the Clinical Randomisation of an Antifibrinolytic in Significant Haemorrhage (CRASH) II study, in which 20,000 trauma patients worldwide were randomly assigned to $1 \mathrm{~g}$ of tranexamic acid for a period of 10 minutes followed by $1 \mathrm{~g}$ infused for a period of eight hours. This results of this trial are due to be published in 2010 [306].

The risk of precipitated thrombosis with the use of the lysine analogues tranexamic acid and $\varepsilon$-aminocaproic 
acid has been of major theoretical concern; however, the Cochrane review of antifibrinolytics cites studies that included more than 8,000 patients receiving lysine analogues and demonstrated no increased risk of either arterial or venous thrombotic events [307]. The lysine analogues are renally excreted and accumulate in individuals with renal failure, therefore dosage should be reduced in patients with renal failure. In practice, mild degrees of renal failure do not seem to affect outcome.

\section{Activated recombinant coagulation factor VII}

Recommendation 28 We suggest that the use of recombinant activated coagulation factor VII (rFVIIa) be considered if major bleeding in blunt trauma persists despite standard attempts to control bleeding and bestpractice use of blood components (Grade 2C).

Rationale rFVIIa is not a first-line treatment for bleeding and will be effective only once sources of major bleeding have been controlled. Once major bleeding from damaged vessels has been stopped, rFVIIa may be helpful to induce coagulation in areas of diffuse small vessel coagulopathic bleeding. rFVIIa should be considered only if first-line treatment with a combination of surgical approaches, best-practice use of blood products (RBCs, platelets, FFP and cryoprecipitate/fibrinogen resulting in Hct above 24\%, platelets above 50,000 $\times$ $10^{9} / \mathrm{l}$ and fibrinogen above 1.5 to $2.0 \mathrm{~g} / \mathrm{l}$ ), the use of antifibrinolytics and correction of severe acidosis, severe hypothermia and hypocalcaemia fail to control bleeding. Because rFVIIa acts on the patient's own coagulation system, adequate numbers of platelets and fibrinogen levels are needed to allow a thrombin burst to be induced by the pharmacological, supraphysiological doses of rFVIIa through direct binding to activated platelets $[308,309] . \mathrm{pH}$ and body temperature should be restored as near to physiological levels as possible because even small reductions in $\mathrm{pH}$ and temperature result in slower coagulation enzyme kinetics [206, $207,310]$. Moreover, hypocalcaemia is frequently present in severely injured patients [251] and so monitoring of ionised calcium is necessary and administration of intravenous calcium may be required [311].

Despite numerous case studies and series reporting that treatment with rFVIIa can be beneficial in the treatment of bleeding following trauma, there are few highquality studies [312-315]. A multi-centre, randomised, double-blind, placebo-controlled study examined the efficacy of rFVIIa in patients with blunt or penetrating trauma [316] and showed that patients with blunt trauma who survived for more than 48 hours, assigned to receive rFVIIa $200 \mu \mathrm{g} / \mathrm{kg}$, after they had received eight units of RBCs, and a second and third dose of $100 \mu \mathrm{g} / \mathrm{mg}$ one and three hours later; had a reduction in RBC transfusion requirements and the need for massive transfusions ( $>20$ units of RBCs), compared with placebo. They also had a significantly reduced incidence of ARDS. In contrast, there were no significant effects in the penetrating trauma patients in this study, although trends toward reduced $\mathrm{RBC}$ requirements and fewer massive transfusions were observed.

The required dose(s) of rFVIIa is still under debate. Whereas the above dosing recommendation is based on the only published RCT available in trauma patients and is also recommended by a group of European experts [317], Israeli guidelines based on findings from a case series of 36 patients who received rFVIIa on a compassionate-use basis in Israel [313] propose an initial dose of $120 \mu \mathrm{g} / \mathrm{kg}$ (between 100 and $140 \mu \mathrm{g} / \mathrm{kg}$ ) and (if required) a second and third dose. Pharmacokinetic modelling techniques have shown that the dose regimen for rFVIIa treatment used in the above cited RCT is capable of providing adequate plasma levels of drug to support haemostasis [318].

If rFVIIa is administered, the patient's next of kin should be informed that rFVIIa is being used outside the currently approved indications (off-label use), especially because the use of rFVIIa may increase the risk of thromboembolic complications [319]. Recent data from a meta-analysis performed by the manufacturer on pooled data from placebo-controlled trials outside current approved indications in various clinical settings included over 2,000 patients and showed a higher risk of arterial thromboembolic adverse events $(5.6 \%$ in patients receiving rFVIIa versus $3.0 \%$ in placebo-treated patients) [320].

\section{Prothrombin complex concentrate}

Recommendation 29 We recommend the use of prothrombin complex concentrate for the emergency reversal of vitamin K-dependent oral anticoagulants (Grade 1B).

Rationale Despite the increasing off-license use of PCC, there are no studies to support its use other than in haemophilia [321-323] or for the rapid reversal of the effect of oral vitamin $\mathrm{K}$ antagonsists [324-326]. With an ageing population, more trauma patients are likely to be taking vitamin $\mathrm{K}$ antagonists, therefore every trauma unit should have an established management policy for these patients. The comparison between outcomes other than speed of reversal of anticoagulation between FFP and PCC has not been established; several clinical trials are in progress, although none relates specifically to trauma patients. Despite some clinical recommendations [327], no clinical studies have been performed to determine whether administration of PCC is efficacious and safe in managing bleeding in trauma patients who are not on vitamin $\mathrm{K}$ antagonists, although a swine model suggests that there may be some advantages [328].

Because the use of PCC carries the theoretical increased risks of both venous and arterial thrombosis 
during the recovery period $[329,330]$, the use of thromboprophylaxis is recommended in patients who have received PCC. Because there are variations in the production of PCC, the dosage should be determined according to the instructions of the individual manufacturer [331]. Research is urgently required to assess whether PCC has a place in the management of the bleeding trauma patient.

\section{Desmopressin}

Recommendation 30 We do not suggest that desmopressin be used routinely in the bleeding trauma patient (Grade 2C). We suggest that desmopressin be considered in refractory microvascular bleeding if the patient has been treated with platelet-inhibiting drugs such as acetylsalicylsalicylic acid (Grade 2C).

Rationale Desmopressin (1-deamino-8-D-arginine) enhances platelet adherence and platelet aggregate growth on human artery subendothelium and was originally licensed for use in von Willebrand disease [332], a disease that occurs in roughly 1 in 100 patients and in whom desmopressin is routinely used. In 1986 the first study was published stating that desmopressin reduces blood loss after cardiac surgery by $30 \%$ in comparison with placebo [333]; however, subsequent studies showed controversial results. Two recently published meta-analyses $[334,335]$ were able to demonstrate either a trend towards a reduced blood loss [334] or a small significant reduction in blood transfusion requirements $(-0.29$ (-0.52 to -0.06$)$ units per patient), but neither study could demonstrate any effect on the course of the disease or mortality. At the same time, concerns arose with respect to possible thromboembolic complications of this procoagulant drug. Whereas Ozal and colleagues described a 2.4-fold increase in risk for myocardial infarction with desmopressin [336], the last meta-analysis from 2008 could not identify a significant increase in myocardial infarction or thrombosis associated with desmopressin. Both meta-analyses stress the need for more RCTs to allow for clear recommendations. On the other hand, patients may benefit from desmopressin if they have been pre-treated with platelet-inhibiting drugs, for example acetylsalicylsalicylic acid [337].

No studies have investigated the effect of desmopressin in the trauma patient, and there is great uncertainty as to whether the results of studies involving nontrauma patients can be applied to bleeding following trauma. Therefore, only a weak recommendation can be made.

\section{Antithrombin III}

Recommendation 31 We do not recommend the use of antithrombin concentrates in the treatment of the bleeding trauma patient (Grade 1C).

Rationale Antithrombin concentrates are indicated in inherited and acquired antithrombin deficiency.
Although antithrombin deficiency does occur in consumptive coagulopathy, this is not an isolated condition; all coagulation factors and physiological anticoagulants undergo consumption under these circumstances. The best replacement therapy is FFP. Clinical studies of antithrombin concentrate in severe blunt trauma and in critical care have shown no benefit $[338,339]$.

\section{Discussion}

This guideline for the management of the bleeding trauma patient is based on a critical appraisal of the published literature, a re-appraisal of the recommendations we published three years ago and a consideration of current clinical practice in areas in which RCTs will never be performed for practical or ethical reasons. In the process of generating this updated version of the guideline, we identified a number of scientific questions that have emerged or were not addressed previously and have developed recommendations to cover these issues. The new and revised recommendations included here reflect both newly available evidence and shifts in general clinical practice. As bedside testing, particularly thrombelastogram-based methodology, and multi-slice CT have become more established in the emergency department setting, we felt a need to update our guideline to discuss the use of these new technologies. We also include new recommendations on the use of tourniquets as an adjunct to halt lifethreatening open extremity injuries, ionised calcium monitoring and treatment, and the use of local haemostatic agents and desmopressin in the bleeding trauma patient. Our recommendations have also been updated to reflect the recent removal of aprotinin as an antifibrinolytic agent from the market. The final draft of this document omitted a draft recommendation on the use of coagulation factor XIII because, although the author group feels that this agent may play a role in the haemostatic management of trauma patients in future, the present lack of evidence in trauma and means of monitoring the therapeutic effect of this compound in many hospitals precludes a specific recommendation at this time.

Although the level of scientific evidence has improved in some areas, particulary those that have come under closer scruitiny in the context of ongoing military conflicts, other areas remain devoid of high-level evidence. Although evidence gathered in a military setting may or may not be readily transferable to the civilian setting, recent experience has shown that there is a need for uniform practices in the management of the traumatically injured patient [340]. This observation renders the need for best-practice guidelines even more acute.

We have excluded animal studies from the evidence considered here, and maintain our opinion that humans 


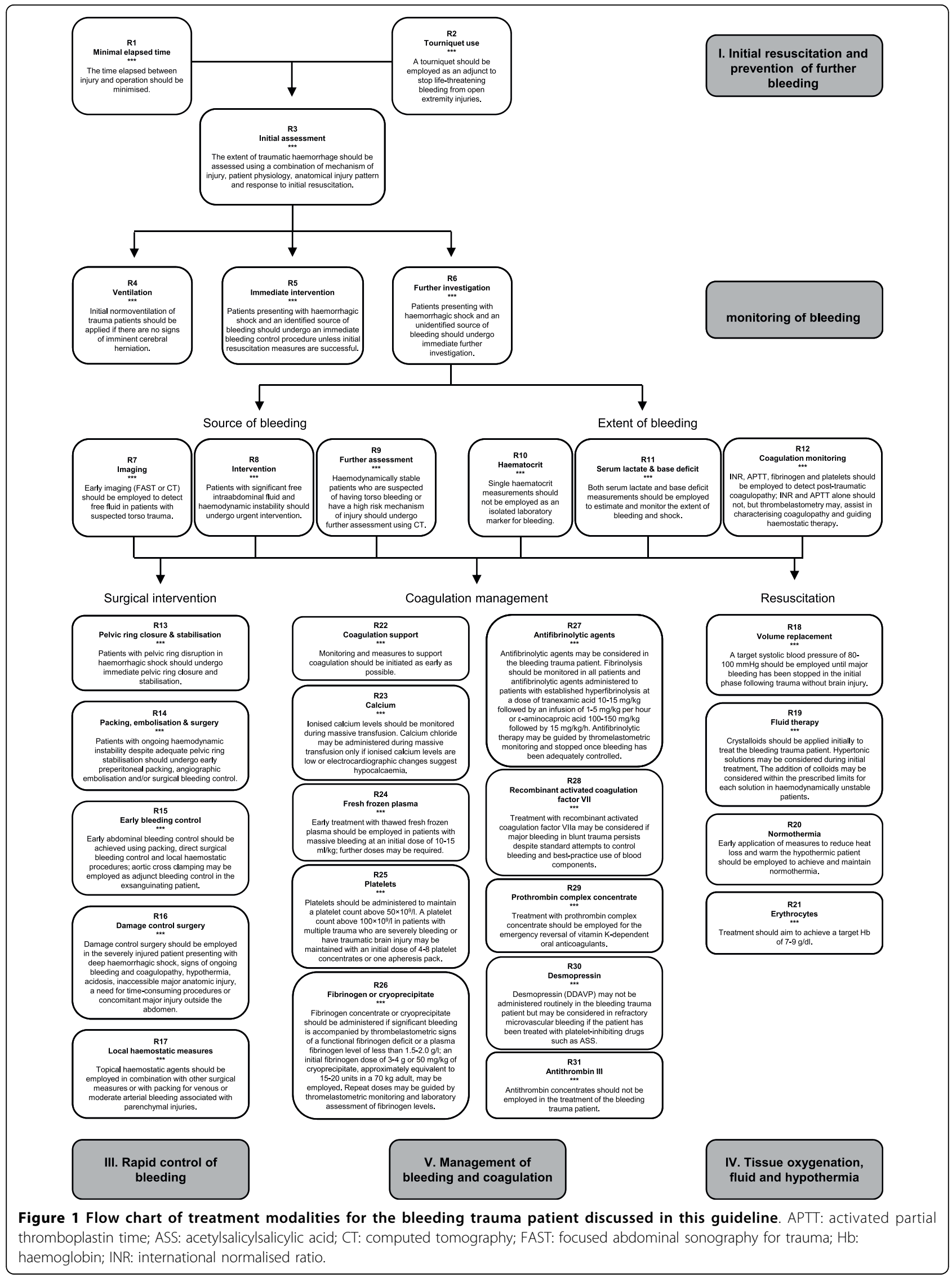


are the best subjects in whom to study human posttraumatic injury [341]. We also continue to concur that in the absence of evidence to the contrary, children and elderly adults, with the exception of those who have been treated with anticoagulant or antiplatelet agents, should generally be managed in the same manner as the normal adult patient. Given the risk of thrombembolic complications, we suggest that the application of procoagulant measures be ceased once haemostasis has been achieved.

All of the recommendations presented here were formulated according to a consensus reached by the author group and the professional societies involved. Figure 1 graphically summarises the recommendations included in this guideline. We have employed the GRADE [14-16] hierarchy or evidence to formulate each recommendation because it allows strong recommendations to be supported by weak clinical evidence in areas in which the ideal clinical RCTs may never be performed. To minimise the bias introduced by individual experts, we employed a nominal group process to develop each recommendation and several Delphi rounds to reach an agreement on the questions to be considered and to reach a final consensus on each recommendation. To ensure that the process included input from all of the relevant specialties, the group comprised a multidisciplinary pan-European group of experts, including the active involvement of representatives from five of the most relevant European professional societies.

\section{Conclusions}

A multidisciplinary approach to management of the traumatically injured patient remains the cornerstone of optimal patient care, and we have made an effort to formulate this guideline in a manner that is widely applicable to a variety of settings in clinical practice. As the volume and level of evidence in this field accumulates, the current state-of-the-art as reflected in this guideline will need to evolve accordingly.

\section{Key messages}

- This clinical practice guideline provides evidencebased recommendations developed by a multidisciplinary task force with respect to the acute management of the bleeding trauma patient, which when implemented may improve patient outcomes.

- Coagulation monitoring and measures to support coagulation should be implemented as early as possible following traumatic injury and used to guide haemostatic therapy.

- A damage control approach to surgical procedures should guide patient management, including closure and stabilisation of pelvic ring disruptions, packing, embolisation and local haemostatic measures.
- This guideline reviews appropriate physiological targets and suggested use and dosing of fluids, blood products and pharmacological agents in the bleeding trauma patient.

- A multidisciplinary approach to management of the traumatically injured patient remains the cornerstone of optimal patient care.

\section{Additional file 1: MeSH terms and limits applied to address} guideline literature queries - 2009. Word file containing MeSH terms and limits applied to address guideline literature queries.

\section{Abbreviations}

ACS: abdominal compartment syndrome; APTT: activated partial thromboplastin time; ARDS: acute respiratory distress syndrome; ATLS: Advanced Trauma Life Support; CT: computed tomography; DPL: diagnostic peritoneal lavage; FAST: focused abdominal sonography for trauma; FFP: fresh frozen plasma; GCS: Glasgow coma score; GRADE: Grading of Recommendations Assessment: Development and Evaluation; $\mathrm{Hb}$ : haemoglobin; Hct: haematocrit; INR: international normalised ratio; IQR: interquartile range; MeSH: medical subject heading; MSCT: multi-slice computed tomography; NIH: National Institutes of Health; PCC: prothrombin complex concentrate; PEEP: positive end-expiratory pressure; PT: prothrombin time; RBC: red blood cell; RCT: randomised controlled trial; rFVIIa: recombinant activated coagulation factor VII; TBI: traumatic brain injury.

\section{Acknowledgements}

The development of this guideline was initiated and performed by the authors as members of the Task Force for Advanced Bleeding Care in Trauma. Members of the task force were compensated for their presence at face-to-face meetings, but not for the time invested in developing and reviewing the recommendations or manuscript. Meeting organisation and medical writing support for literature searches and manuscript preparation were provided by Physicians World Europe GmbH, Mannheim, Germany. Costs incurred for travel, hotel accommodation, meeting facilities, honoraria and preparation of the guideline were supported by unrestricted educational grants from Novo Nordisk Health Care AG, Zurich, Switzerland. The sponsor had no authorship or editorial control over the content of the meetings or any subsequent publication.

Endorsed by the European Society of Anaesthesiology (ESA), the European Society of Intensive Care Medicine (ESICM), the European Shock Society (ESS), the European Society of Trauma and Emergency Surgery (ESTES) and the European Society for Emergency Medicine (EUSEM).

\section{Author details}

'Department of Anaesthesiology, University Hospital Aachen, RWTH Aachen University, Pauwelsstrasse 30, 52074 Aachen, Germany. ${ }^{2}$ Department of Trauma and Orthopedic Surgery, University of Witten/Herdecke, Hospital Cologne Merheim, Ostmerheimerstrasse 200, 51109 Cologne, Germany.

${ }^{3}$ Faculty of Medicine in Hradec Králové, Department of Anaesthesiology and Intensive Care Medicine, University Hospital Hradec Králové, 50005 Hradec Králové, Czech Republic. ${ }^{4}$ Accident and Emergency Department, University of Leicester, Infirmary Square, Leicester LE1 5WW, UK. ${ }^{5}$ Department of Anaesthesia and Intensive Care, University of Paris XI, Faculté de Médecine Paris-Sud, 63 rue Gabriel Péri, 94276 Le Kremlin-Bicêtre, France. ${ }^{6}$ Department of Emergency and Critical Care Medicine, University Hospital Virgen de las Nieves, ctra de Jaén s/n, 18013 Granada, Spain. 'Guy's \& St Thomas' Foundation Trust, Westminster Bridge Road, London, SE1 7EH, UK.

${ }^{8}$ Department of Traumatology, General and Teaching Hospital Celje, 3000 Celje, Slovenia. ${ }^{9}$ Shock and Trauma Center, S. Camillo Hospital, I-00152 Rome, Italy. ${ }^{10}$ Institute for Research in Operative Medicine (IFOM),

Ostmerheimerstrasse 200, 51109 Cologne, Germany. "11 Department of Anaesthesia and Intensive Care, Université Paris Descartes, AP-HP Hopital Cochin, Paris, France. ${ }^{12}$ Department of Surgery and Trauma, Karolinska University Hospital, 17176 Solna, Sweden. ${ }^{13}$ Ludwig-Boltzmann-Institute for 
Experimental and Clinical Traumatology and Lorenz Boehler Trauma Center, Donaueschingenstrasse 13, 1200 Vienna, Austria. ${ }^{14}$ Department of Orthopaedic Surgery and Department of Neurosurgery, University of Colorado Denver School of Medicine, Denver Health Medical Center, 777 Bannock Street, Denver, CO 80204, USA. ${ }^{15}$ Department of Intensive Care, Erasme University Hospital, Université Libre de Bruxelles, Route de Lennik 808, 1070 Brussels, Belgium. ${ }^{16}$ Institute of Anesthesiology, University Hospital Zurich, 8091 Zurich, Switzerland.

\section{Authors' contributions}

All of the authors participated in the formulation of questions to be addressed in the guideline, screening of abstracts and literature, face-to-face and remote consensus-finding processes, drafting, review, revision and approval of the manuscript.

\section{Authors' information}

RR serves as chair of the Advanced Bleeding Care in Trauma (ABC-T) European medical education initiative. $V C$ is a member of the ABC-T European medical education initiative faculty. TJC is a member of the ABC-T European medical education initiative faculty. JD is a member of the ABC-T European medical education initiative faculty. EF-M is a member of the ABCT European medical education initiative faculty. PFS is a member of the ABC-T European medical education initiative faculty. RK represented the European Society of Trauma and Emergency Surgery (ESTES) on the ABC-T Task Force. YO represented the European Society of Intensive Care Medicine (ESICM) on the ABC-T Task Force. LR represented the European Society for Emergency Medicine (EuSEM) on the ABC-T Task Force. AS represented the European Shock Society (ESS) on the ABC-T Task Force. DRS serves as cochair of the Advanced Bleeding Care in Trauma (ABC-T) European medical education initiative and represented the European Society of Anaesthesiology (ESA) on the ABC-T Task Force.

\section{Competing interests}

RR has received honoraria for consulting or lecturing from CSL Behring, Novo Nordisk, Bayer, Air Liquide and Eli Lilly and has received research grant funding from AGA-Linde, Air Liquide, Novo Nordisk, Eli Lilly and Glaxo Wellcome. BB has received honoraria for consulting or lecturing from Novo Nordisk, CSL Behring and Sangart. VC has received honoraria for consulting or lecturing from Fresenius (Czech Republic), Schering-Plough (Czech Republic), B. Braun (Czech Republic) and Novo Nordisk (Czech Republic). TJC has received research funding from the UK National Institute for Health Research, BOC Linde and the Mid Anglian GP Accident Service. He is a trustee of BRAKE (a road safety charity) and the College of Emergency Medicine. JD has received honoraria for consulting or lecturing from Novo Nordisk, LFB Biomédicaments and Hutchinson Technology. EF-M has has received honoraria for consulting or lecturing from Sangart and PULSION Medical Systems. BJH has received honoraria for consulting or lecturing from Bayer, Boehringer Ingelheim, Sanofi Aventis and Novo Nordisk. RK has no competing interests to declare. GN has received honoraria for consulting or lecturing from Novo Nordisk and Sangart and institutional research grant funding from Novo Nordisk. EN has received honoraria for consulting or lecturing from Biotest (Dreieich, Germany), Javelin Pharma (NY, USA), Novo Nordisk (Denmark), MSD Sharp \& Dohme (Haar), Pfizer (Berlin), AstraZeneca (Wedel), B. Braun (Melsungen) and Bristol Myers Squibb (Munich, Germany) and has received institutional support from Mundipharma (Limburg), Cook Ltd. (Bloomington, IN, USA), QRX Pharma (Bedminster, NJ, USA), Ethicon (Norderstedt), KCI (Amstelveen, NL) and Sanofi (Berlin). YO has received institutional support from LFB (Laboratoire français du Fractionnement et des Biotechnologies), Octapharma and Novo Nordisk. LR been involved in educational courses on bleeding control supported by Baxter. AS has no competing interests to declare. PFS has received honoraria for consulting or lecturing from Synthes, Stryker Spine and Novo Nordisk. JLV has received honoraria for consulting or lecturing from AstraZeneca, Edwards Lifesciences, Pfizer, Astellas, Eli Lilly, Ferring, GSK, the Medicines group amd Novo Nordisk and has received research grant funding from AM Pharma, Artisan, Astellas, Curacyte, Eli Lilly, Esai and Novo Nordisk. DRS has received honoraria or travel support for consulting or lecturing from Abbott AG (Baar, Switzerland) Alliance Pharmaceutical Corp. (San Diego, CA, USA) AstraZeneca AG (Zug, Switzerland) Bayer (Schweiz) AG (Zürich, Switzerland) B. Braun Melsungen AG (Melsungen, Germany), Boehringer Ingelheim (Schweiz) GmbH (Basel, Switzerland), CSL Behring GmbH (Hattersheim am Main, Germany), Curacyte
AG (Munich, Germany) Fresenius SE (Bad Homburg v.d.H., Germany), Galenica AG ((including Vifor SA, Villars-sur-Glâne) Bern, Switzerland), GlaxoSmithKline GmbH \& Co. KG (Hamburg, Germany), Janssen-Cilag AG (Baar, Switzerland), Novo Nordisk A/S (Bagsvärd, Denmark), Octapharma AG (Lachen, Switzerland), Organon AG (Pfäffikon/SZ, Switzerland), Oxygen Biotherapeutics (Costa Mesa, CA, USA), Pentapharm GmbH (Munich, Germany), Roche Pharma (Schweiz) AG (Reinach, Switzerland) and ScheringPlough International, Inc. (Kenilworth, NJ, USA). His academic department currently receives grant support from the University of Zurich, the Research Award Center for Zurich Integrative Human Physiology, the Swiss National Science Foundation, the Swiss Foundation for Anesthesia Research, the European Society of Anaesthesiology (ESA), the Swiss Society of Anesthesiology and Reanimation (SGAR), the Gebert Ruef Foundation, the Swiss Life Foundation, the Olga Mayenfisch Foundation, Abbott AG Switzerland, B. Braun Switzerland, UBS Switzerland, Stiftung für Staublungenforschung, Switzerland.

The ABC-T European medical education initiative is managed by Physicians World Europe GmbH (Mannheim, Germany) and supported by educational grants from Novo Nordisk.

Received: 18 January 2010 Revised: 23 March 2010

Accepted: 6 April 2010 Published: 6 April 2010

\section{References}

1. World Health Organisation: cause-specific mortality and morbidity. [http://www.who.int/whosis/whostat/EN_WHS09_Table2.pdf].

2. Cothren $\mathrm{CC}$, Moore EE, Hedegaard HB, Meng K: Epidemiology of urban trauma deaths: a comprehensive reassessment 10 years later. World $J$ Surg 2007, 31:1507-1511.

3. Maegele M, Lefering R, Yucel N, Tjardes T, Rixen D, Paffrath T, Simanski C, Neugebauer E, Bouillon B: Early coagulopathy in multiple injury: an analysis from the German Trauma Registry on 8724 patients. Injury 2007, 38:298-304

4. Brohi K, Singh J, Heron M, Coats T: Acute traumatic coagulopathy. J Trauma 2003, 54:1127-1130.

5. MacLeod JB, Lynn M, McKenney MG, Cohn SM, Murtha M: Early coagulopathy predicts mortality in trauma. J Trauma 2003, 55:39-44.

6. Moore EE, Knudson MM, Jurkovich GJ, Fildes JJ, Meredith JW: Emergency traumatologist or trauma and acute care surgeon: decision time. J Am Coll Surg 2009, 209:394-395.

7. Spahn DR, Rossaint R: Coagulopathy and blood component transfusion in trauma. Br J Anaesth 2005, 95:130-139.

8. Hess JR, Brohi K, Dutton RP, Hauser CJ, Holcomb JB, Kluger Y, MackwayJones K, Parr MJ, Rizoli SB, Yukioka T, Hoyt DB, Bouillon B: The coagulopathy of trauma: a review of mechanisms. J Trauma 2008, 65:748-754.

9. Brohi K, Cohen MJ, Ganter MT, Schultz MJ, Levi M, Mackersie RC, Pittet JF: Acute coagulopathy of trauma: hypoperfusion induces systemic anticoagulation and hyperfibrinolysis. J Trauma 2008, 64:1211-1217, discussion 1217.

10. Rugeri L, Levrat A, David JS, Delecroix E, Floccard B, Gros A, Allaouchiche B, Negrier $C$ : Diagnosis of early coagulation abnormalities in trauma patients by rotation thrombelastography. J Thromb Haemost 2007 5:289-295.

11. Hess JR, Lawson JH: The coagulopathy of trauma versus disseminated intravascular coagulation. J Trauma 2006, 60:S12-19.

12. Spivey M, Parr MJ: Therapeutic approaches in trauma-induced coagulopathy. Minerva Anestesiol 2005, 71:281-289.

13. Spahn DR, Cerny V, Coats TJ, Duranteau J, Fernandez-Mondejar E, Gordini G, Stahel PF, Hunt BJ, Komadina R, Neugebauer E, Ozier Y, Riddez L, Schultz A, Vincent $J \mathrm{~L}$, Rossaint R: Management of bleeding following major trauma: a European guideline. Crit Care 2007, 11:R17.

14. Guyatt G, Gutterman D, Baumann MH, Addrizzo-Harris D, Hylek EM, Phillips B, Raskob G, Lewis SZ, Schunemann H: Grading strength of recommendations and quality of evidence in clinical guidelines: Report from an American College of Chest Physicians task force. Chest 2006, 129:174-181.

15. Brozek JL, Akl EA, Alonso-Coello P, Lang D, Jaeschke R, Williams JW, Phillips B, Lelgemann M, Lethaby A, Bousquet J, Guyatt GH, Schunemann $\mathrm{HJ}$ : Grading quality of evidence and strength of 
recommendations in clinical practice guidelines. Part 1 of 3 . An overview of the GRADE approach and grading quality of evidence about interventions. Allergy 2009, 64:669-677.

16. Brozek JL, Akl EA, Jaeschke R, Lang DM, Bossuyt P, Glasziou P, Helfand M, Ueffing E, Alonso-Coello P, Meerpohl J, Phillips B, Horvath AR, Bousquet J, Guyatt GH, Schunemann HJ: Grading quality of evidence and strength of recommendations in clinical practice guidelines: Part 2 of 3. The GRADE approach to grading quality of evidence about diagnostic tests and strategies. Allergy 2009, 64:1109-1116.

17. [http://www.cebm.net/index.aspx?o=1025].

18. Advanced Bleeding Care in Trauma Slide Kit. [http://www. AdvancedBleedingCare.org].

19. Rossaint R, Cerny V, Coats TJ, Duranteau J, Fernández-Mondéjar E, Gordini G, Stahel PF, Hunt BJ, Neugebauer E, Spahn DR: Key issues in advanced bleeding care in trauma. Shock 2006, 26:322-331.

20. Brown BB: Delphi process: a methodology used for the elicitation of opinions of experts Santa Monica: Rand Corp 1968.

21. Hoyt DB, Bulger EM, Knudson MM, Morris J, lerardi R, Sugerman $H J$, Shackford SR, Landercasper J, Winchell RJ, Jurkovich G, Coffey SC, Chang M, O'Malley KF, Lowry J, Trevisani GT, Cogbill TH: Death in the operating room: an analysis of a multi-center experience. J Trauma 1994, 37:426-432.

22. Smith W, Williams A, Agudelo J, Shannon M, Morgan S, Stahel P, Moore E: Early predictors of mortality in hemodynamically unstable pelvis fractures. J Orthop Trauma 2007, 21:31-37.

23. Martin M, Oh J, Currier H, Tai N, Beekley A, Eckert M, Holcomb J: An analysis of in-hospital deaths at a modern combat support hospital. J Trauma 2009, 66:S51-60, discussion S60-51.

24. Thoburn E, Norris P, Flores R, Goode S, Rodriguez E, Adams V, Campbell S, Albrink M, Rosemurgy A: System care improves trauma outcome: patient care errors dominate reduced preventable death rate. J Emerg Med 1993, 11:135-139.

25. Hill DA, West RH, Roncal S: Outcome of patients with haemorrhagic shock: an indicator of performance in a trauma centre. $J R$ Coll Surg Edinb 1995, 40:221-224.

26. Jayaraman S, Sethi D: Advanced trauma life support training for hospital staff. Cochrane Database Syst Rev 2009, CD004173.

27. Lakstein D, Blumenfeld A, Sokolov T, Lin G, Bssorai R, Lynn M, BenAbraham R: Tourniquets for hemorrhage control on the battlefield: a 4year accumulated experience. J Trauma 2003, 54:S221-225.

28. Beekley AC, Sebesta JA, Blackbourne LH, Herbert GS, Kauvar DS, Baer DG, Walters TJ, Mullenix PS, Holcomb JB: Prehospital tourniquet use in Operation Iraqi Freedom: effect on hemorrhage control and outcomes. J Trauma 2008, 64:S28-37, discussion S37.

29. Brodie S, Hodgetts TJ, Ollerton J, McLeod J, Lambert P, Mahoney P: Tourniquet use in combat trauma: UK military experience. $J R$ Army Med Corps 2007, 153:310-313

30. Kragh JJ Jr, Walters TJ, Baer DG, Fox CJ, Wade CE, Salinas J, Holcomb JB: Survival with emergency tourniquet use to stop bleeding in major limb trauma. Ann Surg 2009, 249:1-7.

31. Swan KG Jr, Wright DS, Barbagiovanni SS, Swan BC, Swan KG: Tourniquets revisited. J Trauma 2009, 66:672-675.

32. Dayan L, Zinmann C, Stahl S, Norman D: Complications associated with prolonged tourniquet application on the battlefield. Mil Med 2008, 173:63-66.

33. Liu CC, Wang CY, Shih HC, Wen YS, Wu JJ, Huang Cl, Hsu HS, Huang MH, Huang MS: Prognostic factors for mortality following falls from height. Injury 2009, 40:595-597.

34. Cinelli SM, Brady P, Rennie CP, Tuluca C, Hall TS: Comparative results of trauma scoring systems in fatal outcomes. Conn Med 2009, 73:261-265.

35. Narci A, Solak O, Turhan-Haktanir N, Aycicek A, Demir Y, Ela Y, Ozkaraca E, Terzi Y: The prognostic importance of trauma scoring systems in pediatric patients. Pediatr Surg Int 2009, 25:25-30.

36. Moore L, Lavoie A, Turgeon AF, Abdous B, Le Sage N, Emond M, Liberman $M$, Bergeron E: The trauma risk adjustment model: a new model for evaluating trauma care. Ann Surg 2009, 249:1040-1046.

37. American College of Surgeons Committee on Trauma: Advanced trauma life support for doctors (ATLS) student course manual Chicago, IL: American College of Surgeons, 82008.

38. Aufderheide TP, Sigurdsson G, Pirrallo RG, Yannopoulos D, McKnite S, von Briesen C, Sparks CW, Conrad CJ, Provo TA, Lurie KG: Hyperventilation- induced hypotension during cardiopulmonary resuscitation. Circulation 2004, 109:1960-1965.

39. Davis DP, Hoyt DB, Ochs M, Fortlage D, Holbrook T, Marshall LK, Rosen P: The effect of paramedic rapid sequence intubation on outcome in patients with severe traumatic brain injury. J Trauma 2003, 54:444-453.

40. Caulfield EV, Dutton RP, Floccare DJ, Stansbury LG, Scalea TM: Prehospital hypocapnia and poor outcome after severe traumatic brain injury. J Trauma 2009, 66:1577-1582, discussion 1583.

41. Davis DP, Idris AH, Sise MJ, Kennedy F, Eastman AB, Velky T, Vilke GM, Hoyt DB: Early ventilation and outcome in patients with moderate to severe traumatic brain injury. Crit Care Med 2006, 34:1202-1208.

42. Davis DP: Early ventilation in traumatic brain injury. Resuscitation 2008, 76:333-340.

43. Warner KJ, Cuschieri J, Copass MK, Jurkovich GJ, Bulger EM: Emergency department ventilation effects outcome in severe traumatic brain injury. J Trauma 2008, 64:341-347.

44. Manley GT, Hemphill JC, Morabito D, Derugin N, Erickson V, Pitts LH, Knudson MM: Cerebral oxygenation during hemorrhagic shock: perils of hyperventilation and the therapeutic potential of hypoventilation. J Trauma 2000, 48:1025-1032, discussion 1032-1023.

45. Blomgren $\mathrm{K}$, Zhu C, Hallin U, Hagberg H: Mitochondria and ischemic reperfusion damage in the adult and in the developing brain. Biochem Biophys Res Commun 2003, 304:551-559.

46. Gajic O, Frutos-Vivar F, Esteban A, Hubmayr RD, Anzueto A: Ventilator settings as a risk factor for acute respiratory distress syndrome in mechanically ventilated patients. Intensive Care Med 2005, 31:922-926.

47. Mascia L, Zavala E, Bosma K, Pasero D, Decaroli D, Andrews P, Isnardi D, Davi A, Arguis MJ, Berardino M, Ducati A: High tidal volume is associated with the development of acute lung injury after severe brain injury: an international observational study. Crit Care Med 2007, 35:1815-1820.

48. Wolthuis EK, Choi G, Dessing MC, Bresser P, Lutter R, Dzoljic M, Poll van der T, Vroom MB, Hollmann M, Schultz MJ: Mechanical ventilation with lower tidal volumes and positive end-expiratory pressure prevents pulmonary inflammation in patients without preexisting lung injury. Anesthesiology 2008, 108:46-54

49. Jackson MR, Olson DW, Beckett WC Jr, Olsen SB, Robertson FM: Abdominal vascular trauma: a review of 106 injuries. Am Surg 1992, 58:622-626.

50. Johnson JW, Gracias VH, Schwab CW, Reilly PM, Kauder DR, Shapiro MB, Dabrowski GP, Rotondo MF: Evolution in damage control for exsanguinating penetrating abdominal injury. J Trauma 2001, 51:261-269, discussion 269-271.

51. Billy L, Amato JJ, Rich NM: Aortic injuries in Vietnam. Surgery 1971 70:385-391.

52. Dean NR, Ledgard JP, Katsaros J: Massive hemorrhage in facial fracture patients: definition, incidence, and management. Plast Reconstr Surg 2009, 123:680-690

53. Frakes MA, Evans T: Major pelvic fractures. Crit Care Nurse 2004, 24:18-30, quiz 31-12.

54. Grotz MR, Gummerson NW, Gansslen A, Petrowsky H, Keel M, Allami MK, Tzioupis C, Trentz O, Krettek C, Pape HC, Giannoudis PV: Staged management and outcome of combined pelvic and liver trauma. An international experience of the deadly duo. Injury 2006, 37:642-651.

55. Cryer HM, Miller FB, Evers BM, Rouben LR, Seligson DL: Pelvic fracture classification: correlation with hemorrhage. J Trauma 1988, 28:973-980

56. Burgess AR, Eastridge BJ, Young JW, Ellison TS, Ellison PS Jr, Poka A, Bathon GH, Brumback RJ: Pelvic ring disruptions: effective classification system and treatment protocols. J Trauma 1990, 30:848-856.

57. Eastridge BJ, Starr A, Minei JP, O'Keefe GE, Scalea TM: The importance of fracture pattern in guiding therapeutic decision-making in patients with hemorrhagic shock and pelvic ring disruptions. J Trauma 2002, 53:446-450, discussion 450-441.

58. Gillman LM, Ball CG, Panebianco N, Al-Kadi A, Kirkpatrick AW: Clinician performed resuscitative ultrasonography for the initial evaluation and resuscitation of trauma. Scand I Trauma Resusc Emerg Med 2009, 17:34.

59. Whitehouse JS, Weigelt JA: Diagnostic peritoneal lavage: a review of indications, technique, and interpretation. Scand I Trauma Resusc Emerg Med 2009, 17:13

60. Stahel PF, Heyde CE, Wyrwich W, Ertel W: [Current concepts of polytrauma management: from ATLS to "damage control"]. Orthopade 2005, 34:823-836. 
61. Gebhard F, Huber-Lang M: Polytrauma-pathophysiology and management principles. Langenbecks Arch Surg 2008, 393:825-831.

62. Huber-Wagner S, Lefering R, Qvick LM, Korner M, Kay MV, Pfeifer KJ, Reiser M, Mutschler W, Kanz KG: Effect of whole-body CT during trauma resuscitation on survival: a retrospective, multicentre study. Lancet 2009, 373(9673):1455-1461

63. Rozycki GS, Newman PG: Surgeon-performed ultrasound for the assessment of abdominal injuries. Adv Surg 1999, 33:243-259.

64. Kretschmer $\mathrm{KH}$, Hauser $\mathrm{H}$ : [Radiologic diagnosis of abdominal trauma]. Radiologe 1998, 38:693-701.

65. Brenchley J, Walker A, Sloan JP, Hassan TB, Venables H: Evaluation of focussed assessment with sonography in trauma (FAST) by UK emergency physicians. Emerg Med J 2006, 23:446-448.

66. Shackford SR, Rogers FB, Osler TM, Trabulsy ME, Clauss DW, Vane DW: Focused abdominal sonogram for trauma: the learning curve of nonradiologist clinicians in detecting hemoperitoneum. J Trauma 1999, 46:553-562, discussion 562-554.

67. Richards JR, Schleper NH, Woo BD, Bohnen PA, McGahan JP: Sonographic assessment of blunt abdominal trauma: a 4-year prospective study. J Clin Ultrasound 2002, 30:59-67.

68. Richards JR, Knopf NA, Wang L, McGahan JP: Blunt abdominal trauma in children: evaluation with emergency US. Radiology 2002, 222:749-754.

69. Rose JS, Levitt MA, Porter J, Hutson A, Greenholtz J, Nobay F, Hilty W: Does the presence of ultrasound really affect computed tomographic scan use? A prospective randomized trial of ultrasound in trauma. J Trauma 2001, 51:545-550.

70. Stengel D, Bauwens K, Sehouli J, Porzsolt F, Rademacher G, Mutze S, Ekkernkamp A: Systematic review and meta-analysis of emergency ultrasonography for blunt abdominal trauma. Br J Surg 2001, 88:901-912.

71. Stengel D, Bauwens K, Rademacher G, Mutze S, Ekkernkamp A: Association between compliance with methodological standards of diagnostic research and reported test accuracy: meta-analysis of focused assessment of US for trauma. Radiology 2005, 236:102-111.

72. Stengel D, Bauwens K, Porzsolt F, Rademacher G, Mutze S, Ekkernkamp A: [Emergency ultrasound for blunt abdominal trauma-meta-analysis update 2003]. Zentralbl Chir 2003, 128:1027-1037.

73. Liu M, Lee CH, P'Eng FK: Prospective comparison of diagnostic peritoneal lavage, computed tomographic scanning, and ultrasonography for the diagnosis of blunt abdominal trauma. J Trauma 1993, 35:267-270.

74. Rohrl B, Sadick M, Diehl S, Obertacke U, Duber C: [Whole-body MSCT of patients after polytrauma: abdominal injuries]. Rofo 2005, 177:1641-1648.

75. Boehm T, Alkadhi H, Schertler T, Baumert B, Roos J, Marincek B, Wildermuth S: [Application of multislice spiral CT (MSCT) in multiple injured patients and its effect on diagnostic and therapeutic algorithms] Rofo 2004, 176:1734-1742.

76. Becker CD, Poletti PA: The trauma concept: the role of MDCT in the diagnosis and management of visceral injuries. Eur Radiol 2005, 15(Suppl 4):D105-109.

77. Weninger P, Mauritz W, Fridrich P, Spitaler R, Figl M, Kern B, Hertz H: Emergency room management of patients with blunt major trauma: evaluation of the multislice computed tomography protocol exemplified by an urban trauma center. J Trauma 2007, 62:584-591.

78. Heyer CM, Rduch G, Kagel T, Lemburg SP, Theisinger A, Bauer T, Muhr G, Nicolas V: [Prospective randomized trial of a modified standard multislice CT protocol for the evaluation of multiple trauma patients]. Rofo 2005, 177:242-249.

79. Navarrete-Navarro P, Vazquez G, Bosch JM, Fernandez E, Rivera R, Carazo E: Computed tomography vs clinical and multidisciplinary procedures for early evaluation of severe abdomen and chest trauma-a cost analysis approach. Intensive Care Med 1996, 22:208-212.

80. Atri M, Hanson JM, Grinblat L, Brofman N, Chughtai T, Tomlinson G: Surgically important bowel and/or mesenteric injury in blunt trauma: accuracy of multidetector CT for evaluation. Radiology 2008, 249:524-533.

81. Marmery $\mathrm{H}$, Shanmuganathan $\mathrm{K}$ : Multidetector-row computed tomography imaging of splenic trauma. Semin Ultrasound CT MR 2006, 27:404-419.

82. Anderson SW, Soto JA, Lucey BC, Burke PA, Hirsch EF, Rhea JT: Blunt trauma: feasibility and clinical utility of pelvic CT angiography performed with 64-detector row CT. Radiology 2008, 246:410-419.

83. Anderson SW, Varghese JC, Lucey BC, Burke PA, Hirsch EF, Soto JA: Blunt splenic trauma: delayed-phase $\mathrm{CT}$ for differentiation of active hemorrhage from contained vascular injury in patients. Radiology 2007, 243:88-95.

84. Fang JF, Chen RJ, Wong YC, Lin BC, Hsu YB, Kao JL, Chen MF: Classification and treatment of pooling of contrast material on computed tomographic scan of blunt hepatic trauma. J Trauma 2000, 49:1083-1088.

85. Linsenmaier U, Krotz M, Hauser H, Rock C, Rieger J, Bohndorf K, Pfeifer KJ, Reiser M: Whole-body computed tomography in polytrauma: techniques and management. Eur Radiol 2002, 12:1728-1740.

86. Albrecht T, von Schlippenbach J, Stahel PF, Ertel W, Wolf KJ: [The role of whole body spiral CT in the primary work-up of polytrauma patientscomparison with conventional radiography and abdominal sonography]. Rofo 2004, 176:1142-1150.

87. Ollerton JE, Sugrue M, Balogh Z, D'Amours SK, Giles A, Wyllie P: Prospective study to evaluate the influence of FAST on trauma patient management. J Trauma 2006, 60:785-791.

88. Farahmand N, Sirlin CB, Brown MA, Shragg GP, Fortlage D, Hoyt DB, Casola G: Hypotensive patients with blunt abdominal trauma: performance of screening US. Radiology 2005, 235:436-443.

89. Kirkpatrick AW, Ball CG, D'Amours SK, Zygun D: Acute resuscitation of the unstable adult trauma patient: bedside diagnosis and therapy. Can J Surg 2008, 51:57-69.

90. Wherrett LJ, Boulanger BR, McLellan BA, Brenneman FD, Rizoli SB, Culhane J, Hamilton P: Hypotension after blunt abdominal trauma: the role of emergent abdominal sonography in surgical triage. J Trauma 1996, 41:815-820.

91. Rozycki GS, Ballard RB, Feliciano DV, Schmidt JA, Pennington SD: Surgeonperformed ultrasound for the assessment of truncal injuries: lessons learned from 1540 patients. Ann Surg 1998, 228:557-567.

92. Paradis NA, Balter S, Davison CM, Simon G, Rose M: Hematocrit as a predictor of significant injury after penetrating trauma. Am J Emerg Med 1997, 15:224-228.

93. Zehtabchi S, Sinert R, Goldman M, Kapitanyan R, Ballas J: Diagnostic performance of serial haematocrit measurements in identifying major injury in adult trauma patients. Injury 2006, 37:46-52.

94. Snyder HS: Significance of the initial spun hematocrit in trauma patients. Am J Emerg Med 1998, 16:150-153.

95. Greenfield RH, Bessen HA, Henneman PL: Effect of crystalloid infusion on hematocrit and intravascular volume in healthy, nonbleeding subjects. Ann Emerg Med 1989, 18:51-55.

96. Kass LE, Tien IY, Ushkow BS, Snyder HS: Prospective crossover study of the effect of phlebotomy and intravenous crystalloid on hematocrit. Acad Emerg Med 1997, 4:198-201.

97. Stamler KD: Effect of crystalloid infusion on hematocrit in nonbleeding patients, with applications to clinical traumatology. Ann Emerg Med 1989, 18:747-749.

98. Broder $\mathrm{G}$, Weil MH: Excess lactate: an index of reversibility of shock in human patients. Science 1964, 143:1457-1459.

99. Wilson M, Davis DP, Coimbra R: Diagnosis and monitoring of hemorrhagic shock during the initial resuscitation of multiple trauma patients: a review. J Emerg Med 2003, 24:413-422.

100. Baron BJ, Scalea TM: Acute blood loss. Emerg Med Clin North Am 1996, 14:35-55.

101. Porter JM, Ivatury RR: In search of the optimal end points of resuscitation in trauma patients: a review. J Trauma 1998, 44:908-914.

102. Bilkovski RN, Rivers EP, Horst HM: Targeted resuscitation strategies after injury. Curr Opin Crit Care 2004, 10:529-538.

103. Vincent $J$, Dufaye $P$, Berre J, Leeman M, Degaute JP, Kahn RJ: Serial lactate determinations during circulatory shock. Crit Care Med 1983, 11:449-451.

104. Abramson D, Scalea TM, Hitchcock R, Trooskin SZ, Henry SM, Greenspan J: Lactate clearance and survival following injury. J Trauma 1993, 35:584-588, discussion 588-589.

105. Manikis P, Jankowski S, Zhang H, Kahn RJ, Vincent JL: Correlation of seria blood lactate levels to organ failure and mortality after trauma. Am J Emerg Med 1995, 13:619-622.

106. Siegel $\mathrm{JH}$ : Immediate versus delayed fluid resuscitation in patients with trauma. N Engl J Med 1995, 332:681, author reply 682-683.

107. Davis JW, Parks SN, Kaups KL, Gladen HE, O'Donnell-Nicol S: Admission base deficit predicts transfusion requirements and risk of complications. J Trauma 1996, 41:769-774

108. Davis JW, Kaups KL, Parks SN: Base deficit is superior to $\mathrm{pH}$ in evaluating clearance of acidosis after traumatic shock. J Trauma 1998, 44:114-118. 
109. Davis JW, Kaups KL: Base deficit in the elderly: a marker of severe injury and death. J Trauma 1998, 45:873-877.

110. Randolph LC, Takacs M, Davis KA: Resuscitation in the pediatric trauma population: admission base deficit remains an important prognostic indicator. J Trauma 2002, 53:838-842.

111. Mikulaschek A, Henry SM, Donovan R, Scalea TM: Serum lactate is not predicted by anion gap or base excess after trauma resuscitation. J Trauma 1996, 40:218-222, discussion 222-214.

112. Yucel $N$, Lefering $R$, Maegele $M$, Vorweg $M$, Tjardes $T$, Ruchholtz $S$, Neugebauer EA, Wappler F, Bouillon B, Rixen D: Trauma Associated Severe Hemorrhage (TASH)-Score: probability of mass transfusion as surrogate for life threatening hemorrhage after multiple trauma. J Trauma 2006, 60:1228-1236, discussion 1236-1227.

113. Ruchholtz S, Pehle B, Lewan U, Lefering R, Muller N, Oberbeck R, Waydhas $C$ : The emergency room transfusion score (ETS): prediction of blood transfusion requirement in initial resuscitation after severe trauma. Transfus Med 2006, 16:49-56.

114. Callaway DW, Shapiro NI, Donnino MW, Baker C, Rosen CL: Serum lactate and base deficit as predictors of mortality in normotensive elderly blunt trauma patients. J Trauma 2009, 66:1040-1044.

115. Paladino L, Sinert R, Wallace D, Anderson T, Yadav K, Zehtabchi S: The utility of base deficit and arterial lactate in differentiating major from minor injury in trauma patients with normal vital signs. Resuscitation 2008, 77:363-368.

116. Mann KG, Butenas S, Brummel K: The dynamics of thrombin formation. Arterioscler Thromb Vasc Biol 2003, 23:17-25.

117. Levrat A, Gros A, Rugeri L, Inaba K, Floccard B, Negrier C, David JS: Evaluation of rotation thrombelastography for the diagnosis of hyperfibrinolysis in trauma patients. Br J Anaesth 2008, 100:792-797.

118. Johansson Pl, Stensballe J: Effect of haemostatic control resuscitation on mortality in massively bleeding patients: a before and after study. Vox Sang 2009, 96:111-118

119. Flint L, Babikian G, Anders M, Rodriguez J, Steinberg S: Definitive control of mortality from severe pelvic fracture. Ann Surg 1990, 211:703-706, discussion 706-707.

120. Agnew SG: Hemodynamically unstable pelvic fractures. Orthop Clin North Am 1994, 25:715-721.

121. Ertel W, Keel M, Eid K, Platz A, Trentz O: Control of severe hemorrhage using C-clamp and pelvic packing in multiply injured patients with pelvic ring disruption. J Orthop Trauma 2001, 15:468-474.

122. Cothren CC, Moore EE: Emergency department thoracotomy for the critically injured patient: Objectives, indications, and outcomes. World J Emerg Surg 2006, 1:4.

123. Miller PR, Moore PS, Mansell E, Meredith JW, Chang MC: External fixation or arteriogram in bleeding pelvic fracture: initial therapy guided by markers of arterial hemorrhage. J Trauma 2003, 54:437-443.

124. Hagiwara A, Minakawa K, Fukushima H, Murata A, Masuda H, Shimazaki S: Predictors of death in patients with life-threatening pelvic hemorrhage after successful transcatheter arterial embolization. J Trauma 2003, 55:696-703.

125. Heetveld MJ, Harris I, Schlaphoff G, Sugrue M: Guidelines for the management of haemodynamically unstable pelvic fracture patients. ANZ J Surg 2004, 74:520-529.

126. Tiemann AH, Schmidt C, Gonschorek O, Josten C: [Use of the "c-clamp" in the emergency treatment of unstable pelvic fractures]. Zentralb/ Chir 2004, 129:245-251.

127. Witschger $P$, Heini $P$, Ganz R: [Pelvic clamps for controlling shock in posterior pelvic ring injuries. Application, biomechanical aspects and initial clinical results]. Orthopade 1992, 21:393-399.

128. Bottlang M, Simpson T, Sigg J, Krieg JC, Madey SM, Long WB: Noninvasive reduction of open-book pelvic fractures by circumferential compression. J Orthop Trauma 2002, 16:367-373.

129. Totterman A, Madsen JE, Skaga NO, Roise O: Extraperitoneal pelvic packing: a salvage procedure to control massive traumatic pelvic hemorrhage. J Trauma 2007, 62:843-852.

130. Smith WR, Moore EE, Osborn P, Agudelo JF, Morgan SJ, Parekh AA, Cothren C: Retroperitoneal packing as a resuscitation technique for hemodynamically unstable patients with pelvic fractures: report of two representative cases and a description of technique. J Trauma 2005, 59:1510-1514.
131. Osborn PM, Smith WR, Moore EE, Cothren CC, Morgan SJ, Williams AE, Stahel PF: Direct retroperitoneal pelvic packing versus pelvic angiography: A comparison of two management protocols for haemodynamically unstable pelvic fractures. Injury 2009, 40:54-60.

132. Verbeek D, Sugrue M, Balogh Z, Cass D, Civil I, Harris I, Kossmann T, Leibman S, Malka V, Pohl A, Rao S, Richardson M, Schuetz M, Ursic C, Wills $\mathrm{V}$ : Acute management of hemodynamically unstable pelvic trauma patients: time for a change? Multicenter review of recent practice. World J Surg 2008, 32:1874-1882.

133. Hoffer EK, Borsa JJ, Bloch RD, Fontaine AB: Endovascular techniques in the damage control setting. Radiographics 1999, 19:1340-1348.

134. Giannoudis PV, Pape HC: Damage control orthopaedics in unstable pelvic ring injuries. Injury 2004, 35:671-677.

135. Agolini SF, Shah K, Jaffe J, Newcomb J, Rhodes M, Reed JF: Arterial embolization is a rapid and effective technique for controlling pelvic fracture hemorrhage. J Trauma 1997, 43:395-399.

136. Hak DJ: The role of pelvic angiography in evaluation and management of pelvic trauma. Orthop Clin North Am 2004, 35:439-443, v.

137. Velmahos GC, Toutouzas KG, Vassiliu P, Sarkisyan G, Chan LS, Hanks SH, Berne TV, Demetriades D: A prospective study on the safety and efficacy of angiographic embolization for pelvic and visceral injuries. J Trauma 2002, 53:303-308, discussion 308.

138. Salim A, Hadjizacharia P, DuBose J, Brown C, Inaba K, Chan L, Margulies DR: Role of anemia in traumatic brain injury. J Am Coll Surg 2008, 207:398-406.

139. Holting T, Buhr HJ, Richter GM, Roeren T, Friedl W, Herfarth C: Diagnosis and treatment of retroperitoneal hematoma in multiple trauma patients. Arch Orthop Trauma Surg 1992, 111:323-326.

140. Geeraerts T, Chhor V, Cheisson G, Martin L, Bessoud B, Ozanne A, Duranteau J: Clinical review: initial management of blunt pelvic trauma patients with haemodynamic instability. Crit Care 2007, 11:204.

141. Hirschberg A, Mattox KL: The crush laparotomy. Top Knife Shropshire: tfm Publishing LtdAllen MK 2006

142. The trauma laparotomy. Manual of Definitive Surgical Trauma London: Hodder ArnoldBoffard K 2007.

143. Ledgerwood AM, Kazmers M, Lucas CE: The role of thoracic aortic occlusion for massive hemoperitoneum. J Trauma 1976, 16:610-615.

144. Millikan JS, Moore EE: Outcome of resuscitative thoracotomy and descending aortic occlusion performed in the operating room. J Trauma 1984, 24:387-392.

145. Hunt PA, Greaves I, Owens WA: Emergency thoracotomy in thoracic trauma-a review. Injury 2006, 37:1-19.

146. Sharp KW, Locicero RJ: Abdominal packing for surgically uncontrollable hemorrhage. Ann Surg 1992, 215:467-474, discussion 474-465.

147. Feliciano DV, Mattox KL, Burch JM, Bitondo CG, Jordan GL Jr: Packing for control of hepatic hemorrhage. J Trauma 1986, 26:738-743.

148. Carmona RH, Peck DZ, Lim RC Jr: The role of packing and planned reoperation in severe hepatic trauma. J Trauma 1984, 24:779-784.

149. Cue Jl, Cryer HG, Miller FB, Richardson JD, Polk HC Jr: Packing and planned reexploration for hepatic and retroperitoneal hemorrhage: critical refinements of a useful technique. J Trauma 1990, 30:1007-1011, discussion 1011-1003.

150. Adam DJ, Fitridge RA, Raptis S: Intra-abdominal packing for uncontrollable haemorrhage during ruptured abdominal aortic aneurysm repair. Eur J Vasc Endovasc Surg 2005, 30:516-519.

151. Rotondo MF, Schwab CW, McGonigal MD, Phillips GR, Fruchterman TM, Kauder DR, Latenser BA, Angood PA: 'Damage control': an approach for improved survival in exsanguinating penetrating abdominal injury. J Trauma 1993, 35:375-382, discussion 382-373.

152. Nicol AJ, Hommes M, Primrose R, Navsaria PH, Krige JE: Packing for control of hemorrhage in major liver trauma. World I Surg 2007, 31:569-574.

153. Stylianos S: Abdominal packing for severe hemorrhage. J Pediatr Surg 1998, 33:339-342.

154. Aydin U, Yazici P, Zeytunlu M, Coker A: Is it more dangerous to perform inadequate packing? World J Emerg Surg 2008, 3:1.

155. MacKenzie S, Kortbeek JB, Mulloy R, Hameed SM: Recent experiences with a multidisciplinary approach to complex hepatic trauma. Injury 2004, 35:869-877.

156. Stone HH, Strom PR, Mullins RJ: Management of the major coagulopathy with onset during laparotomy. Ann Surg 1983, 197:532-535. 
157. Carrillo EH, Spain DA, Wilson MA, Miller FB, Richardson JD: Alternatives in the management of penetrating injuries to the iliac vessels. J Trauma 1998, 44:1024-1029, discussion 1029-1030.

158. Smith MJ, Stiefel MF, Magge S, Frangos S, Bloom S, Gracias V, Le Roux PD: Packed red blood cell transfusion increases local cerebral oxygenation. Crit Care Med 2005, 33:1104-1108.

159. Shapiro MB, Jenkins DH, Schwab CW, Rotondo MF: Damage control: collective review. J Trauma 2000, 49:969-978.

160. Moore EE: Thomas G. Orr Memorial Lecture. Staged laparotomy for the hypothermia, acidosis, and coagulopathy syndrome. Am J Surg 1996, 172:405-410.

161. Rotondo MF, Zonies DH: The damage control sequence and underlying logic. Surg Clin North Am 1997, 77:761-777.

162. Braslow B: Damage control in abdominal trauma. Contemp Surgery 2006, 62:65-74.

163. Hildebrand F, Giannoudis P, Kretteck C, Pape HC: Damage control: extremities. Injury 2004, 35:678-689.

164. Pape HC, Rixen D, Morley J, Husebye EE, Mueller M, Dumont C, Gruner A Oestern HJ, Bayeff-Filoff M, Garving C, Pardini D, van Griensven M, Krettek C, Giannoudis P: Impact of the method of initial stabilization for femoral shaft fractures in patients with multiple injuries at risk for complications (borderline patients). Ann Surg 2007, 246:491-499, discussion 499-501.

165. Rixen D, Grass G, Sauerland S, Lefering R, Raum MR, Yucel N, Bouillon B, Neugebauer EA: Evaluation of criteria for temporary external fixation in risk-adapted damage control orthopedic surgery of femur shaft fractures in multiple trauma patients: "evidence-based medicine" versus "reality" in the trauma registry of the German Trauma Society. J Trauma 2005, 59:1375-1394, discussion 1394-1375.

166. Scalea TM, Boswell SA, Scott JD, Mitchell KA, Kramer ME, Pollak AN: External fixation as a bridge to intramedullary nailing for patients with multiple injuries and with femur fractures: damage control orthopedics. J Trauma 2000, 48:613-621, discussion 621-613.

167. Seyednejad H, Imani M, Jamieson T, Seifalian AM: Topical haemostatic agents. Br J Surg 2008, 95:1197-1225.

168. Recinos G, Inaba K, Dubose J, Demetriades D, Rhee P: Local and systemic hemostatics in trauma: a review. Ulus Travma Acil Cerrahi Derg 2008, 14:175-181.

169. A novel collagen-based composite offers effective hemostasis for multiple surgical indications: Results of a randomized controlled trial. Surgery 2001, 129:445-450.

170. Smith KJ, Skelton HG, Barrett TL, Welch M, Beard J: Histologic and immunohistochemical features in biopsy sites in which bovine collagen matrix was used for hemostasis. J Am Acad Dermatol 1996, 34:434-438.

171. Chapman WC, Clavien PA, Fung J, Khanna A, Bonham A: Effective control of hepatic bleeding with a novel collagen-based composite combined with autologous plasma: results of a randomized controlled trial. Arch Surg 2000, 135:1200-1204, discussion 1205.

172. Sherman R, Chapman WC, Hannon G, Block JE: Control of bone bleeding at the sternum and iliac crest donor sites using a collagen-based composite combined with autologous plasma: results of a randomized controlled trial. Orthopedics 2001, 24:137-141.

173. Oz MC, Cosgrove DM, Badduke BR, Hill JD, Flannery MR, Palumbo R, Topic N: Controlled clinical trial of a novel hemostatic agent in cardiac surgery. The Fusion Matrix Study Group. Ann Thorac Surg 2000, 69:1376-1382.

174. Weaver FA, Hood DB, Zatina M, Messina L, Badduke B: Gelatin-thrombinbased hemostatic sealant for intraoperative bleeding in vascular surgery. Ann Vasc Surg 2002, 16:286-293.

175. Pursifull NF, Morris MS, Harris RA, Morey AF: Damage control management of experimental grade 5 renal injuries: further evaluation of FloSeal gelatin matrix. J Trauma 2006, 60:346-350.

176. Schenk WG, Burks SG, Gagne PJ, Kagan SA, Lawson JH, Spotnitz WD: Fibrin sealant improves hemostasis in peripheral vascular surgery: a randomized prospective trial. Ann Surg 2003, 237:871-876, discussion 876.

177. Molloy DO, Archbold HA, Ogonda L, McConway J, Wilson RK, Beverland DE: Comparison of topical fibrin spray and tranexamic acid on blood loss after total knee replacement: a prospective, randomised controlled trial. J Bone Joint Surg Br 2007, 89:306-309.

178. Drake DB, Wong LG: Hemostatic effect of Vivostat patient-derived fibrin sealant on split-thickness skin graft donor sites. Ann Plast Surg 2003, 50:367-372.
179. Schwartz M, Madariaga J, Hirose R, Shaver TR, Sher L, Chari R, Colonna JO, Heaton N, Mirza D, Adams R, Rees M, Lloyd D: Comparison of a new fibrin sealant with standard topical hemostatic agents. Arch Surg 2004, 139:1148-1154.

180. King DR, Cohn SM, Proctor KG: Modified rapid deployment hemostat bandage terminates bleeding in coagulopathic patients with severe visceral injuries. J Trauma 2004, 57:756-759.

181. Lier H, Krep H, Schroeder S, Stuber F: Preconditions of hemostasis in trauma: a review. The influence of acidosis, hypocalcemia, anemia, and hypothermia on functional hemostasis in trauma. J Trauma 2008, 65:951-960.

182. Dutton RP, Mackenzie CF, Scalea TM: Hypotensive resuscitation during active hemorrhage: impact on in-hospital mortality. J Trauma 2002, 52:1141-1146.

183. Bickell WH, Wall MJ Jr, Pepe PE, Martin RR, Ginger VF, Allen MK, Mattox KL Immediate versus delayed fluid resuscitation for hypotensive patients with penetrating torso injuries. N Engl J Med 1994, 331:1105-1109.

184. Turner J, Nicholl J, Webber L, Cox H, Dixon S, Yates D: A randomised controlled trial of prehospital intravenous fluid replacement therapy in serious trauma. Health Technol Assess 2000, 4:1-57.

185. Sampalis JS, Tamim H, Denis R, Boukas S, Ruest SA, Nikolis A, Lavoie A Fleiszer D, Brown R, Mulder D, Williams II: Ineffectiveness of on-site intravenous lines: is prehospital time the culprit? J Trauma 1997, 43:608-615, discussion 615-607.

186. Burris D, Rhee P, Kaufmann C, Pikoulis E, Austin B, Eror A, DeBraux $S$ Guzzi L, Leppaniemi A: Controlled resuscitation for uncontrolled hemorrhagic shock. J Trauma 1999, 46:216-223.

187. Kwan I, Bunn F, Roberts I: Timing and volume of fluid administration for patients with bleeding. Cochrane Database Syst Rev 2003, CD002245.

188. Madigan MC, Kemp CD, Johnson JC, Cotton BA: Secondary abdominal compartment syndrome after severe extremity injury: are early, aggressive fluid resuscitation strategies to blame? J Trauma 2008, 64:280-285.

189. Sperry JL, Minei JP, Frankel HL, West MA, Harbrecht BG, Moore EE, Maier RV, Nirula R: Early use of vasopressors after injury: caution before constriction. J Trauma 2008, 64:9-14.

190. Velanovich V: Crystalloid versus colloid fluid resuscitation: a meta-analysis of mortality. Surgery 1989, 105:65-71.

191. Bisonni RS, Holtgrave DR, Lawler F, Marley DS: Colloids versus crystalloids in fluid resuscitation: an analysis of randomized controlled trials. J Fam Pract 1991, 32:387-390.

192. Schierhout G, Roberts I: Fluid resuscitation with colloid or crystalloid solutions in critically ill patients: a systematic review of randomised trials. BMJ 1998, 316:961-964.

193. Human albumin administration in critically ill patients: systematic review of randomised controlled trials. Cochrane Injuries Group Albumin Reviewers. BMJ 1998, 317:235-240.

194. Choi PT, Yip G, Quinonez LG, Cook DJ: Crystalloids vs. colloids in fluid resuscitation: a systematic review. Crit Care Med 1999, 27:200-210.

195. Roberts I, Alderson P, Bunn F, Chinnock P, Ker K, Schierhout G: Colloids versus crystalloids for fluid resuscitation in critically ill patients. Cochrane Database Syst Rev 2004, CD000567.

196. Finfer S, Bellomo R, Boyce N, French J, Myburgh J, Norton R: A comparison of albumin and saline for fluid resuscitation in the intensive care unit. $N$ Engl J Med 2004, 350:2247-2256.

197. Bulger EM, Jurkovich GJ, Nathens AB, Copass MK, Hanson S, Cooper C, Liu PY, Neff M, Awan AB, Warner K, Maier RV: Hypertonic resuscitation of hypovolemic shock after blunt trauma: a randomized controlled trial. Arch Surg 2008, 143:139-148, discussion 149.

198. Simma B, Burger R, Falk M, Sacher P, Fanconi S: A prospective, randomized, and controlled study of fluid management in children with severe head injury: lactated Ringer's solution versus hypertonic saline. Crit Care Med 1998, 26:1265-1270.

199. Wade CE, Grady JJ, Kramer GC: Efficacy of hypertonic saline dextran fluid resuscitation for patients with hypotension from penetrating trauma. J Trauma 2003, 54:S144-148.

200. Battison C, Andrews PJ, Graham C, Petty T: Randomized, controlled trial on the effect of a $20 \%$ mannitol solution and a $7.5 \%$ saline $/ 6 \%$ dextran solution on increased intracranial pressure after brain injury. Crit Care Med 2005, 33:196-202, discussion 257-258. 
201. Cooper DJ, Myles PS, McDermott FT, Murray LJ, Laidlaw J, Cooper G, Tremayne AB, Bernard SS, Ponsford J: Prehospital hypertonic saline resuscitation of patients with hypotension and severe traumatic brain injury: a randomized controlled trial. JAMA 2004, 291:1350-1357.

202. Banks CJ, Furyk JS: Review article: hypertonic saline use in the emergency department. Emerg Med Australas 2008, 20:294-305.

203. Bernabei AF, Levison MA, Bender JS: The effects of hypothermia and injury severity on blood loss during trauma laparotomy. J Trauma 1992, 33:835-839.

204. Hoey BA, Schwab CW: Damage control surgery. Scand J Surg 2002, 91:92-103.

205. Krishna G, Sleigh JW, Rahman H: Physiological predictors of death in exsanguinating trauma patients undergoing conventional trauma surgery. Aust N Z J Surg 1998, 68:826-829.

206. Watts DD, Trask A, Soeken K, Perdue P, Dols S, Kaufmann C: Hypothermic coagulopathy in trauma: effect of varying levels of hypothermia on enzyme speed, platelet function, and fibrinolytic activity. J Trauma 1998, 44:846-854.

207. DeLoughery TG: Coagulation defects in trauma patients: etiology, recognition, and therapy. Crit Care Clin 2004, 20:13-24.

208. Eddy VA, Morris JA Jr, Cullinane DC: Hypothermia, coagulopathy, and acidosis. Surg Clin North Am 2000, 80:845-854.

209. Watts DD, Roche M, Tricarico R, Poole F, Brown JJ Jr, Colson GB, Trask AL, Fakhry SM: The utility of traditional prehospital interventions in maintaining thermostasis. Prehosp Emerg Care 1999, 3:115-122.

210. Kim SH, Stezoski SW, Safar P, Capone A, Tisherman S: Hypothermia and minimal fluid resuscitation increase survival after uncontrolled hemorrhagic shock in rats. J Trauma 1997, 42:213-222.

211. Wladis A, Hahn RG, Hjelmqvist H, Brismar B, Kjellstrom BT: Acute hemodynamic effects of induced hypothermia in hemorrhagic shock: an experimental study in the pig. Shock 2001, 15:60-64.

212. Mclntyre LA, Fergusson DA, Hebert PC, Moher D, Hutchison JS: Prolonged therapeutic hypothermia after traumatic brain injury in adults: a systematic review. JAMA 2003, 289:2992-2999.

213. Henderson WR, Dhingra VK, Chittock DR, Fenwick JC, Ronco JJ: Hypothermia in the management of traumatic brain injury. A systematic review and meta-analysis. Intensive Care Med 2003, 29:1637-1644.

214. Polderman $\mathrm{KH}$ : Application of therapeutic hypothermia in the intensive care unit. Opportunities and pitfalls of a promising treatment modalityPart 2: Practical aspects and side effects. Intensive Care Med 2004, 30:757-769.

215. Jiang JY, Xu W, Li WP, Gao GY, Bao YH, Liang YM, Luo QZ: Effect of longterm mild hypothermia or short-term mild hypothermia on outcome of patients with severe traumatic brain injury. $J$ Cereb Blood Flow Metab 2006, 26:771-776.

216. Hutchison JS, Ward RE, Lacroix J, Hebert PC, Barnes MA, Bohn DJ, Dirks PB, Doucette S, Fergusson D, Gottesman R, Joffe AR, Kirpalani HM, Meyer PG, Morris KP, Moher D, Singh RN, Skippen PW: Hypothermia therapy after traumatic brain injury in children. N Engl J Med 2008, 358:2447-2456.

217. Liu WG, Qiu WS, Zhang Y, Wang WM, Lu F, Yang XF: Effects of selective brain cooling in patients with severe traumatic brain injury: a preliminary study. J Int Med Res 2006, 34:58-64.

218. Peterson K, Carson S, Carney N: Hypothermia treatment for traumatic brain injury: a systematic review and meta-analysis. J Neurotrauma 2008 25:62-71.

219. Brux A, Girbes AR, Polderman KH: [Controlled mild-to-moderate hypothermia in the intensive care unit]. Anaesthesist 2005, 54:225-244.

220. Polderman KH, van Zanten AR, Nipshagen MD, Girbes AR: Induced hypothermia in traumatic brain injury: effective if properly employed. Crit Care Med 2004, 32:313-314.

221. Peyrou V, Lormeau JC, Herault JP, Gaich C, Pfliegger AM, Herbert JM: Contribution of erythrocytes to thrombin generation in whole blood. Thromb Haemost 1999, 81:400-406.

222. Bombeli T, Spahn DR: Updates in perioperative coagulation: physiology and management of thromboembolism and haemorrhage. $\mathrm{Br} J$ Anaesth 2004, 93:275-287.

223. Valeri CR, Cassidy G, Pivacek LE, Ragno G, Lieberthal W, Crowley JP, Khuri SF, Loscalzo J: Anemia-induced increase in the bleeding time: implications for treatment of nonsurgical blood loss. Transfusion 2001 41:977-983.
224. Quaknine-Orlando B, Samama CM, Riou B, Bonnin P, Guillosson JJ, Beaumont $J$, Coriat $P$ : Role of the hematocrit in a rabbit model of arterial thrombosis and bleeding. Anesthesiology 1999, 90:1454-1461.

225. Iwata H, Kaibara M: Activation of factor IX by erythrocyte membranes causes intrinsic coagulation. Blood Coagul Fibrinolysis 2002, 13:489-496.

226. Iwata H, Kaibara M, Dohmae N, Takio K, Himeno R, Kawakami S: Purification, identification, and characterization of elastase on erythrocyte membrane as factor IX-activating enzyme. Biochem Biophys Res Commun 2004, 316:65-70.

227. Iselin BM, Willimann PF, Seifert B, Casutt M, Bombeli T, Zalunardo MP, Pasch T, Spahn DR: Isolated reduction of haematocrit does not compromise in vitro blood coagulation. Br J Anaesth 2001, 87:246-249.

228. Hebert PC, Wells G, Blajchman MA, Marshall J, Martin C, Pagliarello G, Tweeddale M, Schweitzer I, Yetisir E: A multicenter, randomized, controlled clinical trial of transfusion requirements in critical care. Transfusion Requirements in Critical Care Investigators, Canadian Critical Care Trials Group. N Engl J Med 1999, 340:409-417.

229. Mclntyre L, Hebert PC, Wells G, Fergusson D, Marshall J, Yetisir E, Blajchman $\mathrm{MJ}$ : Is a restrictive transfusion strategy safe for resuscitated and critically ill trauma patients? J Trauma 2004, 57:563-568, discussion 568 .

230. Malone DL, Dunne J, Tracy JK, Putnam AT, Scalea TM, Napolitano LM: Blood transfusion, independent of shock severity, is associated with worse outcome in trauma. J Trauma 2003, 54:898-905, discussion 905-897.

231. Charles A, Shaikh AA, Walters M, Huehl S, Pomerantz R: Blood transfusion is an independent predictor of mortality after blunt trauma. Am Surg 2007, 73:1-5.

232. Robinson WP, Ahn J, Stiffler A, Rutherford EJ, Hurd H, Zarzaur BL, Baker CC, Meyer AA, Rich PB: Blood transfusion is an independent predictor of increased mortality in nonoperatively managed blunt hepatic and splenic injuries. J Trauma 2005, 58:437-444, discussion 444-435.

233. Weinberg JA, McGwin G Jr, Marques MB, Cherry SA, Reiff DA, Kerby JD, Rue LW: Transfusions in the less severely injured: does age of transfused blood affect outcomes? J Trauma 2008, 65:794-798.

234. Croce MA, Tolley EA, Claridge JA, Fabian TC: Transfusions result in pulmonary morbidity and death after a moderate degree of injury. J Trauma 2005, 59:19-23, discussion 23-24.

235. Chaiwat O, Lang JD, Vavilala MS, Wang J, MacKenzie EJ, Jurkovich GJ, Rivara FP: Early packed red blood cell transfusion and acute respiratory distress syndrome after trauma. Anesthesiology 2009, 110:351-360.

236. Silverboard H, Aisiku I, Martin GS, Adams M, Rozycki G, Moss M: The role of acute blood transfusion in the development of acute respiratory distress syndrome in patients with severe trauma. J Trauma 2005, 59:717-723.

237. Claridge JA, Sawyer RG, Schulman AM, McLemore EC, Young JS: Blood transfusions correlate with infections in trauma patients in a dosedependent manner. Am Surg 2002, 68:566-572.

238. Marik PE, Corwin HL: Efficacy of red blood cell transfusion in the critically ill: a systematic review of the literature. Crit Care Med 2008, 36:2667-2674.

239. Madjdpour C, Spahn DR: Allogeneic red blood cell transfusions: efficacy, risks, alternatives and indications. $\mathrm{Br} J$ Anaesth 2005, 95:33-42.

240. Leal-Noval SR, Munoz-Gomez M, Arellano-Orden V, Marin-Caballos A, Amaya-Villar R, Marin A, Puppo-Moreno A, Ferrandiz-Millon C, FloresCordero JM, Murillo-Cabezas F: Impact of age of transfused blood on cerebral oxygenation in male patients with severe traumatic brain injury. Crit Care Med 2008, 36:1290-1296.

241. Leal-Noval SR, Rincon-Ferrari MD, Marin-Niebla A, Cayuela A, ArellanoOrden V, Marin-Caballos A, Amaya-Villar R, Ferrandiz-Millon C, MurilloCabeza F: Transfusion of erythrocyte concentrates produces a variable increment on cerebral oxygenation in patients with severe traumatic brain injury: a preliminary study. Intensive Care Med 2006, 32:1733-1740.

242. Zygun DA, Nortje J, Hutchinson PJ, Timofeev I, Menon DK, Gupta AK: The effect of red blood cell transfusion on cerebral oxygenation and metabolism after severe traumatic brain injury. Crit Care Med 2009, 37:1074-1078.

243. Sharma D, Vavilala MS: Transfusion improves cerebral oxygenation but not always. Crit Care Med 2009, 37:1166-1167.

244. Carlson AP, Schermer CR, Lu SW: Retrospective evaluation of anemia and transfusion in traumatic brain injury. J Trauma 2006, 61:567-571. 
245. Brohi K, Cohen MJ, Ganter MT, Matthay MA, Mackersie RC, Pittet JF: Acute traumatic coagulopathy: initiated by hypoperfusion: modulated through the protein C pathway? Ann Surg 2007, 245:812-818.

246. Brohi K, Cohen MJ, Davenport RA: Acute coagulopathy of trauma: mechanism, identification and effect. Curr Opin Crit Care 2007, 13:680-685.

247. Kashuk JL, Moore EE, Johnson JL, Haenel J, Wilson M, Moore JB, Cothren CC, Biffl WL, Banerjee A, Sauaia A: Postinjury life threatening coagulopathy: is 1:1 fresh frozen plasma:packed red blood cells the answer? J Trauma 2008, 65:261-270, discussion 270-271.

248. Gonzalez EA, Moore FA, Holcomb JB, Miller CC, Kozar RA, Todd SR, Cocanour CS, Balldin BC, McKinley BA: Fresh frozen plasma should be given earlier to patients requiring massive transfusion. J Trauma 2007, 62:112-119.

249. Cotton BA, Au BK, Nunez TC, Gunter OL, Robertson AM, Young PP: Predefined massive transfusion protocols are associated with a reduction in organ failure and postinjury complications. J Trauma 2009, 66:41-48, discussion 48-49.

250. Scalea TM, Bochicchio KM, Lumpkins K, Hess JR, Dutton R, Pyle A, Bochicchio GV: Early aggressive use of fresh frozen plasma does not improve outcome in critically injured trauma patients. Ann Surg 2008, 248:578-584

251. Vivien B, Langeron O, Morell E, Devilliers C, Carli PA, Coriat P, Riou B: Early hypocalcemia in severe trauma. Crit Care Med 2005, 33:1946-1952.

252. Perkins JG, Cap AP, Weiss BM, Reid TJ, Bolan CD: Massive transfusion and nonsurgical hemostatic agents. Crit Care Med 2008, 36:S325-339.

253. Stanworth SJ, Brunskill SJ, Hyde CJ, McClelland DB, Murphy MF: Is fresh frozen plasma clinically effective? A systematic review of randomized controlled trials. Br J Haematol 2004, 126:139-152.

254. O'Shaughnessy DF, Atterbury C, Bolton Maggs P, Murphy M, Thomas D, Yates S, Williamson LM: Guidelines for the use of fresh-frozen plasma, cryoprecipitate and cryosupernatant. Br J Haematol 2004, 126:11-28.

255. Practice Guidelines for blood component therapy: A report by the American Society of Anesthesiologists Task Force on Blood Component Therapy. Anesthesiology 1996, 84:732-747.

256. Ho AM, Dion PW, Cheng CA, Karmakar MK, Cheng G, Peng Z, Ng YW: A mathematical model for fresh frozen plasma transfusion strategies during major trauma resuscitation with ongoing hemorrhage. Can J Surg 2005, 48:470-478.

257. Toy P, Popovsky MA, Abraham E, Ambruso DR, Holness LG, Kopko PM, McFarland JG, Nathens AB, Silliman CC, Stroncek D: Transfusion-related acute lung injury: definition and review. Crit Care Med 2005, 33:721-726.

258. Palfi M, Berg S, Ernerudh J, Berlin G: A randomized controlled trial oftransfusion-related acute lung injury: is plasma from multiparous blood donors dangerous? Transfusion 2001, 41:317-322.

259. Holness L, Knippen MA, Simmons L, Lachenbruch PA: Fatalities caused by TRALI. Transfus Med Rev 2004, 18:184-188.

260. Dara SI, Rana R, Afessa B, Moore SB, Gajic O: Fresh frozen plasma transfusion in critically ill medical patients with coagulopathy. Crit Care Med 2005, 33:2667-2671.

261. Holcomb JB, Wade CE, Michalek JE, Chisholm GB, Zarzabal LA, Schreiber MA, Gonzalez EA, Pomper GJ, Perkins JG, Spinella PC, Williams KL, Park MS: Increased plasma and platelet to red blood cell ratios improves outcome in 466 massively transfused civilian trauma patients. Ann Surg 2008, 248:447-458.

262. Duchesne JC, Hunt JP, Wahl G, Marr AB, Wang YZ, Weintraub SE, Wright MJ, McSwain NE Jr: Review of current blood transfusions strategies in a mature level I trauma center: were we wrong for the last 60 years? J Trauma 2008, 65:272-276, discussion 276-278.

263. Cotton BA, Gunter OL, Isbell J, Au BK, Robertson AM, Morris JA Jr, St Jacques $P$, Young PP: Damage control hematology: the impact of a trauma exsanguination protocol on survival and blood product utilization. J Trauma 2008, 64:1177-1182, discussion 1182-1183.

264. Gunter OL Jr, Au BK, Isbell JM, Mowery NT, Young PP, Cotton BA: Optimizing outcomes in damage control resuscitation: identifying blood product ratios associated with improved survival. J Trauma 2008, 65:527-534.

265. Borgman MA, Spinella PC, Perkins JG, Grathwohl KW, Repine T, Beekley AC, Sebesta J, Jenkins D, Wade CE, Holcomb JB: The ratio of blood products transfused affects mortality in patients receiving massive transfusions at a combat support hospital. J Trauma 2007, 63:805-813.
266. Spinella PC, Perkins JG, Grathwohl KW, Beekley AC, Niles SE, McLaughlin DF, Wade CE, Holcomb JB: Effect of plasma and red blood cell transfusions on survival in patients with combat related traumatic injuries. J Trauma 2008, 64:S69-77, discussion S77-78.

267. Snyder CW, Weinberg JA, McGwin G Jr, Melton SM, George RL, Reiff DA, Cross JM, Hubbard-Brown J, Rue LW, Kerby JD: The relationship of blood product ratio to mortality: survival benefit or survival bias? I Trauma 2009, 66:358-362, discussion 362-364.

268. Etemadrezaie H, Baharvahdat H, Shariati Z, Lari SM, Shakeri MT, Ganjeifar B: The effect of fresh frozen plasma in severe closed head injury. Clin Neurol Neurosurg 2007, 109:166-171.

269. Guidelines for transfusion for massive blood loss. A publication of the British Society for Haematology. British Committee for Standardization in Haematology Blood Transfusion Task Force. Clin Lab Haematol 1988, 10:265-273.

270. Norfolk DR, Ancliffe PJ, Contreras M, Hunt BJ, Machin SJ, Murphy WG, Williamson LM: Consensus Conference on Platelet Transfusion, Royal College of Physicians of Edinburgh, 27-28 November 1997. Synopsis of background papers. Br J Haematol 1998, 101:609-617.

271. Stainsby D, MacLennan S, Hamilton PJ: Management of massive blood loss: a template guideline. Br J Anaesth 2000, 85:487-491.

272. Samama CM, Djoudi R, Lecompte T, Nathan-Denizot N, Schved JF: Perioperative platelet transfusion: recommendations of the Agence Francaise de Securite Sanitaire des Produits de Sante (AFSSaPS) 2003. Can J Anaesth 2005, 52:30-37.

273. Hunt BJ: Indications for therapeutic platelet transfusions. Blood Rev 1998 12:227-233.

274. Consensus conference. Platelet transfusion therapy. JAMA 1987, 257:1777-1780.

275. Practice parameter for the use of fresh-frozen plasma, cryoprecipitate, and platelets. Fresh-Frozen Plasma, Cryoprecipitate, and Platelets Administration Practice Guidelines Development Task Force of the College of American Pathologists. JAMA 1994, 271:777-781.

276. Horsey PJ: Multiple trauma and massive transfusion. Anaesthesia 1997, 52:1027-1029.

277. Mehta S, Watson JT: Platelet rich concentrate: basic science and current clinical applications. J Orthop Trauma 2008, 22:432-438.

278. Cinat ME, Wallace WC, Nastanski F, West J, Sloan S, Ocariz J, Wilson SE: Improved survival following massive transfusion in patients who have undergone trauma. Arch Surg 1999, 134:964-968, discussion 968-970.

279. Furie B, Furie BC: Mechanisms of thrombus formation. N Engl J Med 2008, 359:938-949.

280. Hiippala ST, Myllyla GJ, Vahtera EM: Hemostatic factors and replacement of major blood loss with plasma-poor red cell concentrates. Anesth Analg 1995, 81:360-365.

281. Charbit B, Mandelbrot L, Samain E, Baron G, Haddaoui B, Keita H, Sibony O, Mahieu-Caputo D, Hurtaud-Roux MF, Huisse MG, Denninger MH, de Prost D: The decrease of fibrinogen is an early predictor of the severity of postpartum hemorrhage. J Thromb Haemost 2007, 5:266-273.

282. Karlsson M, Ternstrom L, Hyllner M, Baghaei F, Nilsson S, Jeppsson A: Plasma fibrinogen level, bleeding, and transfusion after on-pump coronary artery bypass grafting surgery: a prospective observational study. Transfusion 2008, 48:2152-2158.

283. Fenger-Eriksen C, Lindberg-Larsen M, Christensen AQ, Ingerslev J, Sorensen $\mathrm{B}$ : Fibrinogen concentrate substitution therapy in patients with massive haemorrhage and low plasma fibrinogen concentrations. $\mathrm{Br} J$ Anaesth 2008, 101:769-773.

284. Stinger HK, Spinella PC, Perkins JG, Grathwohl KW, Salinas J, Martini WZ, Hess JR, Dubick MA, Simon CD, Beekley AC, Wolf SE, Wade CE, Holcomb JB: The ratio of fibrinogen to red cells transfused affects survival in casualties receiving massive transfusions at an army combat support hospital. J Trauma 2008, 64:S79-85, discussion S85.

285. Fenger-Eriksen C, Jensen TM, Kristensen BS, Jensen KM, Tonnesen E, Ingerslev J, Sorensen B: Fibrinogen substitution improves whole blood clot firmness after dilution with hydroxyethyl starch in bleeding patients undergoing radical cystectomy: a randomized, placebo-controlled clinical trial. J Thromb Haemost 2009, 7:795-802.

286. Weinstock N, Ntefidou M: SSC International Collaborative Study to establish the first high fibrinogen plasma reference material for use with 
different fibrinogen assay techniques. J Thromb Haemost 2006, 4:1825-1827.

287. Mackie IJ, Kitchen S, Machin SJ, Lowe GD: Guidelines on fibrinogen assays. Br J Haematol 2003, 121:396-404.

288. Hiippala ST: Dextran and hydroxyethyl starch interfere with fibrinogen assays. Blood Coagul Fibrinolysis 1995, 6:743-746.

289. Thompson GH, Florentino-Pineda I, Armstrong DG, Poe-Kochert C. Fibrinogen levels following Amicar in surgery for idiopathic scoliosis. Spine 2007, 32:368-372.

290. Wei KL, Lin CJ, Lai KA: Changes in coagulatory profile after orthopedic surgery. J Formos Med Assoc 1995, 94:541-547.

291. Karlsson M, Ternstrom L, Hyllner M, Baghaei F, Flinck A, Skrtic S, Jeppsson A: Prophylactic fibrinogen infusion reduces bleeding after coronary artery bypass surgery. A prospective randomised pilot study. Thromb Haemost 2009, 102:137-144.

292. Weinkove R, Rangarajan S: Fibrinogen concentrate for acquired hypofibrinogenaemic states. Transfus Med 2008, 18:151-157.

293. Mangano DT, Miao Y, Vuylsteke A, Tudor IC, Juneja R, Filipescu D, Hoeft A, Fontes ML, Hillel Z, Ott E, Titov T, Dietzel C, Levin J: Mortality associated with aprotinin during 5 years following coronary artery bypass graft surgery. JAMA 2007, 297:471-479.

294. Mangano DT, Tudor IC, Dietzel C: The risk associated with aprotinin in cardiac surgery. N Engl I Med 2006, 354:353-365.

295. US Food and Drug Administration: Safety Information Trasylol (aprotinin injection). [http://www.fda.gov/Safety/MedWatch/SafetyInformation/ SafetyAlertsforHumanMedicalProducts/ucm095103.htm]

296. Fergusson DA, Hebert PC, Mazer CD, Fremes S, MacAdams C, Murkin JM, Teoh K, Duke PC, Arellano R, Blajchman MA, Bussieres JS, Cote D, Karski J, Martineau R, Robblee JA, Rodger M, Wells G, Clinch J, Pretorius R: A comparison of aprotinin and lysine analogues in high-risk cardiac surgery. N Engl I Med 2008, 358:2319-2331.

297. Anderson L, Nilsoon IM, Colleen S, Granstrand B, Melander B: Role of urokinase and tissue plasminogen activator in sustaining bleeding and the management thereof with EACA and AMCA. Ann N T Acad Sci 1968, 146:642-658.

298. Fiechtner BK, Nuttall GA, Johnson ME, Dong Y, Sujirattanawimol N, Oliver WC Jr, Sarpal RS, Oyen L, Ereth MH: Plasma tranexamic acid concentrations during cardiopulmonary bypass. Anesth Analg 2001, 92:1131-1136.

299. Horrow JC, Van Riper DF, Strong MD, Grunewald KE, Parmet JL: The doseresponse relationship of tranexamic acid. Anesthesiology 1995, 82:383-392.

300. Diprose P, Herbertson MJ, O'Shaughnessy D, Deakin CD, Gill RS: Reducing allogeneic transfusion in cardiac surgery: a randomized double-blind placebo-controlled trial of antifibrinolytic therapies used in addition to intra-operative cell salvage. Br J Anaesth 2005, 94:271-278.

301. Royston D, Bidstrup BP, Taylor KM, Sapsford RN: Effect of aprotinin on need for blood transfusion after repeat open-heart surgery. Lancet 1987, 2:1289-1291

302. Levi M, Cromheecke ME, de Jonge E, Prins MH, de Mol BJ, Briet E, Buller HR: Pharmacological strategies to decrease excessive blood loss in cardiac surgery: a meta-analysis of clinically relevant endpoints. Lancet 1999, 354:1940-1947.

303. Dietrich W, Spannagl M, Boehm J, Hauner K, Braun S, Schuster T, Busley R: Tranexamic acid and aprotinin in primary cardiac operations: an analysis of 220 cardiac surgical patients treated with tranexamic acid or aprotinin. Anesth Analg 2008, 107:1469-1478.

304. Elwatidy S, Jamjoom Z, Elgamal E, Zakaria A, Turkistani A, El-Dawlatly A: Efficacy and safety of prophylactic large dose of tranexamic acid in spine surgery: a prospective, randomized, double-blind, placebocontrolled study. Spine 2008, 33:2577-2580.

305. Wong J, El Beheiry H, Rampersaud YR, Lewis S, Ahn H, De Silva Y, Abrishami A, Baig N, McBroom RJ, Chung F: Tranexamic Acid reduces perioperative blood loss in adult patients having spinal fusion surgery. Anesth Analg 2008, 107:1479-1486.

306. CRASH II Study: [http://www.crash.lshtm.ac.uk].

307. Henry DA, Moxey AJ, Carless PA, O'Connell D, McClelland B, Henderson KM, Sly K, Laupacis A, Fergusson D: Anti-fibrinolytic use for minimising perioperative allogeneic blood transfusion. Cochrane Database Syst Rev 2001, CD001886.

308. Hoffman M, Monroe DM: A cell-based model of hemostasis. Thromb Haemost 2001, 85:958-965.
309. Hoffman M: A cell-based model of coagulation and the role of factor Vlla. Blood Rev 2003, 17(Suppl 1):S1-5.

310. Luna GK, Maier RV, Pavlin EG, Anardi D, Copass MK, Oreskovich MR: Incidence and effect of hypothermia in seriously injured patients. J Trauma 1987, 27:1014-1018.

311. James MF, Roche AM: Dose-response relationship between plasma ionized calcium concentration and thrombelastography. J Cardiothorac Vasc Anesth 2004, 18:581-586

312. Martinowitz U, Kenet G, Segal E, Luboshitz J, Lubetsky A, Ingerslev J, Lynn M: Recombinant activated factor VII for adjunctive hemorrhage control in trauma. J Trauma 2001, 51:431-438, discussion 438-439.

313. Martinowitz U, Michaelson M: Guidelines for the use of recombinant activated factor VII (rFVIla) in uncontrolled bleeding: a report by the Israeli Multidisciplinary rFVIlla Task Force. J Thromb Haemost 2005, 3:640-648.

314. Harrison TD, Laskosky J, Jazaeri O, Pasquale MD, Cipolle M: "Low-dose" recombinant activated factor VII results in less blood and blood product use in traumatic hemorrhage. J Trauma 2005, 59:150-154.

315. Dutton RP, McCunn M, Hyder M, D'Angelo M, O'Connor J, Hess JR, Scalea TM: Factor VIla for correction of traumatic coagulopathy. I Trauma 2004, 57:709-718, discussion 718-709.

316. Boffard KD, Riou B, Warren B, Choong PI, Rizoli S, Rossaint R, Axelsen M, Kluger Y: Recombinant factor Vlla as adjunctive therapy for bleeding control in severely injured trauma patients: two parallel randomized, placebo-controlled, double-blind clinical trials. J Trauma 2005, 59:8-15, discussion 15-18.

317. Vincent JL, Rossaint R, Riou B, Ozier Y, Zideman D, Spahn DR: Recommendations on the use of recombinant activated factor VII as an adjunctive treatment for massive bleeding - a European perspective. Crit Care 2006, 10:R120.

318. Klitgaard T, Tabanera YPR, Boffard K, lau PT, Warren B, Rizoli S, Rossaint R, Kluger Y, Riou B: Pharmacokinetics of recombinant activated factor VII in trauma patients with severe bleeding. Crit Care 2006, 10:R104.

319. O'Connell KA, Wood JJ, Wise RP, Lozier JN, Braun MM: Thromboembolic adverse events after use of recombinant human coagulation factor Vlla. JAMA 2006, 295:293-298.

320. rFVlla; eptacog alfa; NovoSeven. European Public Assessment Report 2009 [http://www.emea.europa.eu].

321. Goodknight SH, Common HH, Lovrein EW: Letter: Factor VIII inhibitor following surgery for epidural hemorrhage in hemophilia: successful therapy with a concentrate containing factors II, VII, IX, and X. J Pediatr 1976, 88:356-357.

322. Sheikh AA, Abildgaard CF: Medical management of extensive spinal epidural hematoma in a child with factor IX deficiency. Pediatr Emerg Care 1994, 10:26-29.

323. Penner JA: Management of haemophilia in patients with high-titre inhibitors: focus on the evolution of activated prothrombin complex concentrate AUTOPLEX T. Haemophilia 1999, 5(Suppl 3):1-9.

324. Cartmill M, Dolan G, Byrne JL, Byrne PO: Prothrombin complex concentrate for oral anticoagulant reversal in neurosurgical emergencies. Br J Neurosurg 2000, 14:458-461.

325. Konig SA, Schick U, Dohnert J, Goldammer A, Vitzthum HE: Coagulopathy and outcome in patients with chronic subdural haematoma. Acta Neurol Scand 2003, 107:110-116.

326. Baglin TP, Keeling DM, Watson HG: Guidelines on oral anticoagulation (warfarin): third edition-2005 update. Br J Haematol 2006, 132:277-285.

327. Fries $D$, Innerhofer $P$, Schobersberger $W$ : Time for changing coagulation management in trauma-related massive bleeding. Curr Opin Anaesthesiol 2009, 22:267-274.

328. Dickneite G, Pragst I: Prothrombin complex concentrate vs fresh frozen plasma for reversal of dilutional coagulopathy in a porcine trauma model. Br J Anaesth 2009, 102:345-354.

329. Pruthi RK, Heit JA, Green MM, Emiliusen LM, Nichols WL, Wilke JL, Gastineau DA: Venous thromboembolism after hip fracture surgery in a patient with haemophilia B and factor V Arg506Gln (factor V Leiden). Haemophilia 2000, 6:631-634.

330. Abildgaard CF: The management of bleeding in hemophilia. Adv Pediatr 1969, 16:365-390.

331. Kessler CM: Urgent reversal of warfarin with prothrombin complex concentrate: where are the evidence-based data? J Thromb Haemost 2006, 4:963-966. 
332. Ruggeri ZM, Mannucci PM, Lombardi R, Federici AB, Zimmerman TS Multimeric composition of factor VIII/von Willebrand factor following administration of DDAVP: implications for pathophysiology and therapy of von Willebrand's disease subtypes. Blood 1982, 59:1272-1278.

333. Salzman EW, Weinstein MJ, Weintraub RM, Ware JA, Thurer RL, Robertson L, Donovan A, Gaffney T, Bertele V, Troll J, Smith MS, Chute BA: Treatment with desmopressin acetate to reduce blood loss after cardiac surgery. A double-blind randomized trial. N Engl J Med 1986, 314:1402-1406.

334. Carless PA, Henry DA, Moxey AJ, O'Connell D, McClelland B, Henderson KM, Sly K, Laupacis A, Fergusson D: Desmopressin for minimising perioperative allogeneic blood transfusion. Cochrane Database Syst Rev 2004, CD001884

335. Crescenzi G, Landoni G, Biondi-Zoccai G, Pappalardo F, Nuzzi M, Bignami E, Fochi O, Maj G, Calabro MG, Ranucci M, Zangrillo A: Desmopressin reduces transfusion needs after surgery: a meta-analysis of randomized clinical trials. Anesthesiology 2008, 109:1063-1076.

336. Ozal E, Kuralay E, Bingol H, Cingoz F, Ceylan S, Tatar H: Does tranexamic acid reduce desmopressin-induced hyperfibrinolysis? J Thorac Cardiovasc Surg 2002, 123:539-543.

337. Laupacis A, Fergusson D: Drugs to minimize perioperative blood loss in cardiac surgery: meta-analyses using perioperative blood transfusion as the outcome. The International Study of Peri-operative Transfusion (ISPOT) Investigators. Anesth Analg 1997, 85:1258-1267.

338. Waydhas C, Nast-Kolb D, Gippner-Steppert C, Trupka A, Pfundstein C, Schweiberer $L$, Jochum M: High-dose antithrombin III treatment of severely injured patients: results of a prospective study. J Trauma 1998, 45:931-940.

339. Diaz-Cremades JM, Lorenzo R, Sanchez M, Moreno MJ, Alsar MJ, Bosch JM Fajardo L, Gonzalez D, Guerrero D: Use of antithrombin III in critical patients. Intensive Care Med 1994, 20:577-580.

340. Hoyt DB, Dutton RP, Hauser CJ, Hess JR, Holcomb JB, Kluger Y, MackwayJones K, Parr MJ, Rizoli SB, Yukioka T, Bouillon B: Management of Coagulopathy in the Patients With Multiple Injuries: Results From an International Survey of Clinical Practice. J Trauma 2008, 65:755-765.

341. Parr MJ, Bouillon B, Brohi K, Dutton RP, Hauser CJ, Hess JR, Holcomb JB, Kluger Y, Mackway-Jones K, Rizoli SB, Yukioka T, Hoyt DB: Traumatic coagulopathy: where are the good experimental models? J Trauma 2008, 65:766-771.

doi: $10.1186 /$ cc8943

Cite this article as: Rossaint et al:: Management of bleeding following major trauma: an updated European guideline. Critical Care 2010 14:R52.

\section{Submit your next manuscript to BioMed Central and take full advantage of:}

- Convenient online submission

- Thorough peer review

- No space constraints or color figure charges

- Immediate publication on acceptance

- Inclusion in PubMed, CAS, Scopus and Google Scholar

- Research which is freely available for redistribution

Submit your manuscript at www.biomedcentral.com/submit
Biomed Central 